\title{
Comparison of satellite-based evapotranspiration estimates over the Tibetan Plateau
}

\author{
Jian Peng ${ }^{1}$, Alexander Loew ${ }^{1,5}$, Xuelong Chen ${ }^{2}$, Yaoming $\mathrm{Ma}^{3,4}$, and Zhongbo $\mathrm{Su}^{2}$ \\ ${ }^{1}$ Max Planck Institute for Meteorology, 20146 Hamburg, Germany \\ ${ }^{2}$ Faculty of Geo-Information Science and Earth Observation, University of Twente, Enschede 7500 AE, the Netherlands \\ ${ }^{3}$ Key Laboratory of Tibetan Environment Changes and Land Surface Processes, Institute of Tibetan Plateau Research, \\ Chinese Academy of Sciences, Beijing 100101, China \\ ${ }^{4}$ CAS Center for Excellence in Tibetan Plateau Earth Sciences, Chinese Academy of Sciences, Beijing 100101, China \\ ${ }^{5}$ Department of Geography, Ludwig-Maximilians Universität München (LMU), 80333 Munich, Germany
}

Correspondence to: Jian Peng (jian.peng@mpimet.mpg.de)

Received: 23 December 2015 - Published in Hydrol. Earth Syst. Sci. Discuss.: 2 February 2016

Revised: 11 July 2016 - Accepted: 20 July 2016 - Published: 8 August 2016

\begin{abstract}
The Tibetan Plateau (TP) plays a major role in regional and global climate. The understanding of latent heat (LE) flux can help to better describe the complex mechanisms and interactions between land and atmosphere. Despite its importance, accurate estimation of evapotranspiration (ET) over the TP remains challenging. Satellite observations allow for ET estimation at high temporal and spatial scales. The purpose of this paper is to provide a detailed cross-comparison of existing ET products over the TP. Six available ET products based on different approaches are included for comparison. Results show that all products capture the seasonal variability well with minimum ET in the winter and maximum ET in the summer. Regarding the spatial pattern, the High resOlution Land Atmosphere surface Parameters from Space (HOLAPS) ET demonstrator dataset is very similar to the LandFlux-EVAL dataset (a benchmark ET product from the Global Energy and Water Cycle Experiment), with decreasing ET from the south-east to northwest over the TP. Further comparison against the LandFluxEVAL over different sub-regions that are decided by different intervals of normalised difference vegetation index (NDVI), precipitation, and elevation reveals that HOLAPS agrees best with LandFlux-EVAL having the highest correlation coefficient $(R)$ and the lowest root mean square difference (RMSD). These results indicate the potential for the application of the HOLAPS demonstrator dataset in understanding the land-atmosphere-biosphere interactions over the TP. In order to provide more accurate ET over the TP,
\end{abstract}

model calibration, high accuracy forcing dataset, appropriate in situ measurements as well as other hydrological data such as runoff measurements are still needed.

\section{Introduction}

Evapotranspiration (ET) is an essential nexus of energy and water cycles through the mass and energy interactions between land and atmosphere (Jung et al., 2010; Peng et al., 2013a). The estimation of spatially distributed ET has been advanced by the progress of satellite remote sensing technology. However, remote sensing techniques do not allow to directly inverting ET from space (Peng et al., 2013b; K. Zhang et al., 2016). Different methods have been therefore developed to estimate ET with the use of physical variables that are sensed by satellite and are related to the evaporation process (Kalma et al., 2008; Wang and Dickinson, 2012). In recent years, a number of global ET products have been generated with the availability of long-term global satellite products and progress in computer science (Zhang et al., 2010; Vinukollu et al., 2011b; Miralles et al., 2011; Fisher et al., 2008). Some of these global products can even provide ET with a spatial resolution less than $10 \mathrm{~km}$ and temporal resolution less than $3 \mathrm{~h}$ (Mu et al., 2007; Miralles et al., 2016; Loew et al., 2016). HOLAPS (High resOlution Land Atmosphere surface Parameters from Space) demonstrator dataset is one of them. HOLAPS is actually a frame- 
work that can provide surface energy and water fluxes at sub-hourly timescales and spatial resolutions at the kilometre scale. It is also worth noting that very high spatial resolution (on the order of $10 \mathrm{~m}$ ) ET product at regional scale can be provided by ALEXI/DisALEXI based on thermal observations from polar and geostationary orbiting satellites (Anderson et al., 2011, 2007). Although these global ET products have been applied to many applications such as multidecadal trend analysis (Y. Zhang et al., 2016; Zhang et al., 2015; Miralles et al., 2014; Jiménez et al., 2011), large discrepancies exist in these products. Within the Global Energy and Water Cycle Experiment (GEWEX) LandFlux initiative, Mueller et al. (2011) conducted a comparison of existing global latent heat (LE) products from either land surface models, re-analysis, or satellite estimates, and found that the global mean LE over land was $45 \pm 5 \mathrm{~W} \mathrm{~m}^{-2}$, with a spread of $20 \mathrm{~W} \mathrm{~m}^{-2}$. In addition, a synthesis dataset has also been generated within the GEWEX LandFlux-EVAL initiative, which provides LE at monthly timescale and a spatial resolution of $1^{\circ}$ (Mueller et al., 2013). Recently, several studies have evaluated commonly used ET retrieval algorithms, including Penman-Monteith (PM) algorithm, the Priestley-Taylor (PT) model, and the Surface Energy Balance System (SEBS) (Su, 2002), which are driven by the same forcing dataset at both FLUXNET tower and global scales (Vinukollu et al., 2011b; Miralles et al., 2016; Michel et al., 2016; McCabe et al., 2016; Ershadi et al., 2014). To develop a more accurate global LE product, improvements of the parameterisation and sensitivity analysis of the model to forcing dataset are still needed (Michel et al., 2016; McCabe et al., 2016). Note that the energy equivalent for ET is referred to as LE flux, which is used interchangeable with ET in this paper.

Nevertheless, theses global ET products have great potentials for global and regional hydrological applications. In this study, the performances of the widely used global ET products will be investigated over the Tibetan Plateau (TP), as the ET over the TP is of great importance and research interest. The TP has strong impacts on weather and climate at the regional to global scale and controls climatic and environmental changes in Asia and elsewhere in the Northern Hemisphere (Ma et al., 2008). The knowledge of ET is essential for the study of land-atmosphere interactions, and assessment of the impacts of and feedbacks to the global change (Shi and Liang, 2014). In order to characterise the distribution of ET over the TP, different methods using micrometeorological measurements (Yang et al., 2003; Lee et al., 2012; Chen et al., 2013b; Zhang et al., 2007), remote sensing products (Ma et al., 2014, 2006; Chen et al., 2013a) and the combined use of both data sources (Ma et al., 2003, 2011; You et al., 2014) have been investigated over the last decades. In addition, land surface models have also been applied to simulate ET over the TP (Gerken et al., 2012; Yang et al., 2009). However, accurate estimation of ET over TP is still a challenge due to the limitations of the above approaches. Specifically, the observation-based methods are not adequate for determination of regional ET due to the limited spatial representativeness of meteorological stations, while the remote sensing products are only available under clear-sky conditions. The models results are limited by the accuracy of input parameters and the uncertainties of model parameterisation over complicated topography and highly heterogeneous areas of the TP (Shi and Liang, 2013b). The existing global ET products, especially those with high spatial and temporal resolutions such as HOLAPS, provide a potentially applicable ET dataset over the TP. Although the global ET products have been validated against FLUXNET measurements, the reliability of spatial and temporal patterns of them over the TP is still unknown. A comprehensive analysis of the characteristics of the LE over the TP based on the state-of-the-art global ET products has not yet been conducted. Therefore, the main objective of this study is to provide a detailed crosscomparison of the different existing ET products over the TP. Through this study, the following research questions will be addressed. (1) Do existing global ET products show consistent spatial and temporal patterns over the TP? (2) Are there systematic deviations between the different data products, which can be explained by different climate or surface conditions? The study will focus mainly on a cross-comparison between the different existing datasets due to a lack of appropriate reference data in the region, as will be discussed.

\section{Study area}

The TP, known as the third pole of the Earth (Qiu, 2008), covers approximately the latitude from 26 to $40^{\circ} \mathrm{N}$, and longitude from 75 to $105^{\circ} \mathrm{E}$, with an area of $2500000 \mathrm{~km}^{2}$. It is the highest and largest plateau in the world, with very complex terrain and an average elevation higher than $4000 \mathrm{~m}$ above sea level (a.s.l.) (Fig. 1) (Frauenfeld et al., 2005; Ma et al., 2008). Due to its unique and special geographical position and physical environment, the climate of TP is influenced by both the Asian monsoon and westerlies (Yang et al., 2014), and it has profound thermal and dynamical impacts on atmospheric circulation over China, the whole of East Asia, and even the entire globe (Cui and Graf, 2009; You et al., 2014). Specifically, the TP reaches the middle troposphere and influences the atmospheric circulation through mechanical forcing (Yanai and Li, 1994). On the other hand, the thermal forcing of the TP enhances the Asian summer monsoon and influences its variability (Duan and $\mathrm{Wu}, 2005$; Lau et al., 2006). In addition, the melting water from snow and glaciers in TP is the source of many rivers in southern and eastern Asia such as Yangtze and Ganges-Brahmaputra. Therefore, the TP is also known as "the Asian water tower", supporting approximately $25 \%$ of the world's population (Immerzeel et al., 2010; Xu et al., 2008). Quantitative estimation of the water and energy cycles over the TP is of great significance for the study of land-atmosphere-biosphere interactions, and 


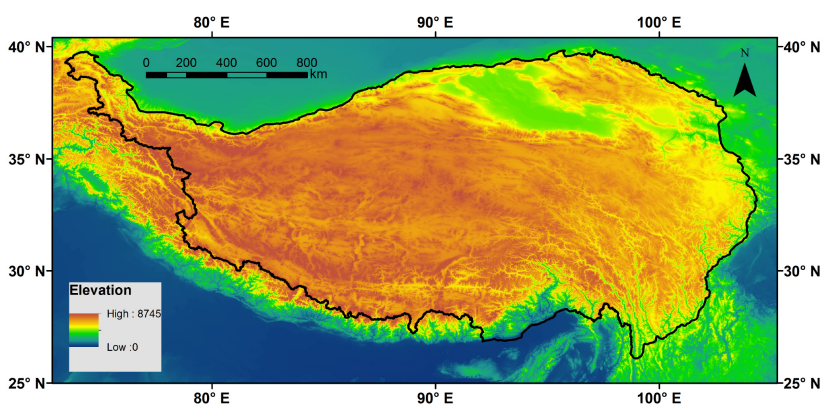

Figure 1. Map of the location and topography of the Tibetan Plateau.

understanding its response to climate change (Sellers et al., 1997; Yang et al., 2014).

\section{Data and methods}

\subsection{Data}

Different groups of algorithms have been developed to estimate ET from satellite data. These comprise (1) surface energy balance models forced either by satellite remote sensing or re-analysis data (Bastiaanssen et al., 1998; $\mathrm{Su}, 2002)$, (2) the methods based on PM or PT equations (Fisher et al., 2008; Miralles et al., 2011; Mu et al., 2007; Zhang et al., 2015), (3) spatial variability methods (Peng et al., 2013b; Peng and Loew, 2014; Roerink et al., 2000). Among them, the PM algorithm, the PT model, and the SEBS are widely used, and have been explored by both the GEWEX LandFlux-EVAL initiative and the Water Cycle Multi-mission Observation Strategy EvapoTranspiration (WACMOS-ET) project. Therefore, three LE datasets based these models and driven by the same forcing data are compared over the TP in this study. These datasets are

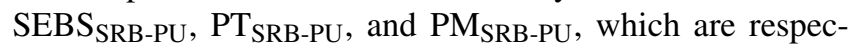
tively based on the SEBS, PT, and PM algorithms but driven by the same input radiation from the surface radiation budget (SRB) (Stackhouse et al., 2011) and meteorological forcing datasets from Princeton University (PU) (Vinukollu et al., 2011a). The three datasets used in this study were obtained from the Princeton University Terrestrial Hydrology Research Group. In addition, to investigate the impact of forcing data on the estimation of LE, another recently released SEBS dataset ( $\mathrm{SEBS}_{\mathrm{Chen}}$ ) is also included in this study (Chen et al., 2014). Different from SEBS SRB-PU, $_{\text {SEBS }}$ Chen is driven by the meteorological forcing data obtained from the Institute of Tibetan Plateau Research, Chinese Academy of Sciences (ITP, CAS), which were generated based on 740 weather stations operated by the China Meteorological Administration. In addition, the recently developed HOLAPS LE demonstrator dataset is also included for comparison. A brief description of these products is presented below. For detailed algo- rithms and parameterisations of these datasets, the reader is referred to the original articles: SEBS $_{\mathrm{SRB}-\mathrm{PU}}, \mathrm{PT}_{\mathrm{SRB}-\mathrm{PU}}$ and PM $_{\text {SRB-PU }}$ (Vinukollu et al., 2011a), SEBS ${ }_{\text {Chen }}$ (Chen et al., 2014), and HOLAPS (Loew et al., 2016).

\subsubsection{SEBS}

SEBS is a one-source energy balance algorithm, which firstly calculates the sensible heat flux $(H)$ based on the MoninObukhov theory (Monin and Obukhov, 1954) with the requirement of surface temperature, air temperature gradient, and the parameterisation of aerodynamic resistance. To constrain $H$ within a lower and upper boundary, two limiting conditions are considered. Under dry limit, the ET is equal to 0 and $H$ is at its maximum, whereas the ET reaches its potential rate and $H$ is at its minimum under wet limit. After the $H$ is calculated, ET can be obtained through closing the energy balance with the availability of net radiation and ground heat flux. SEBS has already been widely validated with ground-based measurements over different areas. Two SEBS datasets are included in the comparison. The

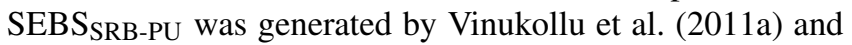
based on radiation from SRB and meteorological forcing datasets from PU (Vinukollu et al., 2011a), while SEBS Chen $_{\text {}}$ estimated ET with meteorological forcing data from the ITP,

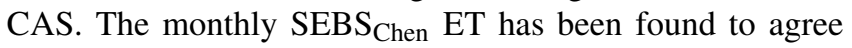
well with ground-based measurements over China (Chen et al., 2014). The comparison of these two SEBS datasets can show the impact of the forcing dataset on the estimation of LE for the same type of model.

\subsubsection{PMSRB-PU}

The PMSRB-PU is estimated based on a revised PM model (Mu et al., 2007, 2011), which has been widely used to estimate global ET. Due to its Penman-Monteith equation basis, the PM model has a high demand for inputs, with a highlevel parameterisation of the aerodynamic and surface resistances using meteorological data and vegetation phenology. In contrast to most PM-based ET models, two improvements

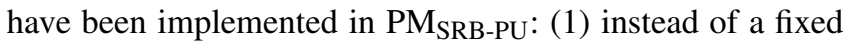
value, a biome-specific value for the mean potential stomatal conductance is applied; (2) the aerodynamic resistance parameterisation used by SEBS is applied here to account for wind speed and boundary layer stability (Vinukollu et al., 2011a). The PMSRB-PU is based on the same forcing data as SEBS $_{\text {SRB-PU }}$.

\subsubsection{PT SRB-PU $_{\text {S }}$}

The PT-JPL model by Fisher et al. (2008) is used to estimate PT SRB-PU. Different from the PM model, the PT model does not require the parameterisation of the aerodynamic and surface resistances. Traditionally, the PT equation (Priestley and Taylor, 1972) is used to estimate potential ET, while the PT-JPL model is adjusted to estimate actual ET through con- 
Table 1. Summary of the datasets used in our study.

\begin{tabular}{lllll}
\hline Dataset & ET scheme & $\begin{array}{l}\text { Spatial } \\
\text { resolution }\end{array}$ & $\begin{array}{l}\text { Temporal } \\
\text { resolution }\end{array}$ & Reference \\
\hline PM $_{\text {SRB-PU }}$ & Penman-Monteith & $1^{\circ}$ & daily & Vinukollu et al. (2011a) \\
PT $_{\text {SRB-PU }}$ & Priestley-Taylor & $1^{\circ}$ & daily & Vinukollu et al. (2011a) \\
SEBS $_{\text {SRB-PU }}$ & SEBS & $1^{\circ}$ & daily & Vinukollu et al. (2011a) \\
SEBS $_{\text {Chen }}$ & SEBS & $0.1^{\circ}$ & daily & Chen et al. (2014) \\
HOLAPS & Priestley-Taylor & $5 \mathrm{~km}$ & half hourly & Loew et al. (2016) \\
LandFlux-EVAL & Synthesis product & $1^{\circ}$ & monthly & Mueller et al. (2013) \\
\hline
\end{tabular}

sidering the ecophysiological stress factors based on atmospheric moisture and vegetation indices. This implies that the forcing data required for $\mathrm{PT}_{\mathrm{SRB}-\mathrm{PU}}$ are quite comparable to that of PM $\mathrm{M}_{\mathrm{SRB}-\mathrm{PU}}$. The PT $\mathrm{T}_{\mathrm{SRB}-\mathrm{PU}}$ relies on the same forcing datasets as SEBS $S_{S R B-P U}$ and PMSRB-PU, which provides the possibility to investigate the performance of different ET models driven by the same forcing data over the TP.

\subsubsection{HOLAPS}

The HOLAPS LE product was generated from HOLAPS framework, which makes use of meteorological drivers coming exclusively from a globally available satellite and reanalysis datasets and is based on a state-of-the-art land surface scheme (Loew et al., 2016). It is based on a radiation module, a planetary boundary layer model, a soil module, and a general module for the exchange of energy and moisture at the surface layer. HOLAPS can ensure internal consistency of the different energy and water fluxes and provide estimates at high temporal $(<1 \mathrm{~h})$ and spatial $(\sim 5 \mathrm{~km})$ resolutions. Good agreement with in situ measurements have also been found by Loew et al. (2016) when compared against 48 FLUXNET stations worldwide. The details of the HOLAPS framework and relevant evaluation results can be found in the reference of Loew et al. (2016).

The validation of different LE datasets against in situ measurements over the TP is not possible for the current study period due to (a) the access to suitable in situ measurements is not possible and (b) spatial representativeness of the existing FLUXNET towers for areas of only several square kilometres. Therefore, the above LE datasets are cross-compared with LandFlux-EVAL benchmark product in the current analysis. LandFlux-EVAL is a merged synthesis LE product based on a total of 14 datasets including land surface model output, observations-based estimates, and atmospheric reanalyses (Mueller et al., 2013). It provides the best guess estimate of LE for the first time based on the existing global LE datasets, and also provides the uncertainty range of the absolute LE values (interquartile range of the merged synthesis LE products). Note that the merged LE dataset agreed well with precipitation minus runoff over large river basins around the world (Mueller et al., 2011), and it has been used to evaluate the LE simulations of the fifth phase of the
Coupled model Inter-comparison project (CMIP5) (Mueller and Seneviratne, 2014). To further demonstrate the validity of LandFlux-EVAL benchmark product over the TP, we also compared it to precipitation, which is one of the most important driving factors for LE. It should be noted here that LandFlux-EVAL also includes satellite-based LE datasets that are estimated from PM and PT algorithms. However, the $\mathrm{PM}_{\text {SRB-PU }}$ and PT $\mathrm{PRB}_{\mathrm{SR}-\mathrm{PU}}$ datasets used in the current analysis are different from those datasets. They are based on revised PM and PT approaches, which also account for the evaporation from canopy intercepted precipitation (Vinukollu et al., 2011a). In addition, the forcing datasets used for PM $\mathrm{M}_{\mathrm{SRB}-\mathrm{PU}}$ and PT $_{\text {SRB-PU }}$ are also different from that used for PM and PT datasets in LandFlux-EVAL. For example, the radiation

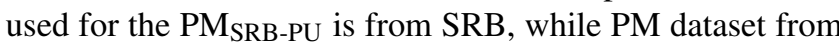
LandFlux-EVAL uses radiation from International Satellite Cloud Climatology Project (ISCCP). A summary of these datasets is given in Table 1. For detailed information about each product, the reader is referred to the relevant publications.

\subsection{Methods}

\subsubsection{Data preprocessing}

All of the datasets were firstly aggregated to monthly mean values over the common time period 2001-2005, which corresponds to the temporal resolution of LandFlux-EVAL benchmark product and the time period currently covered by the HOLAPS demonstrator dataset (Loew et al., 2016; Mueller et al., 2013). To make an unbiased comparison with LandFlux-EVAL dataset, HOLAPS and SEBS Chen were further aggregated to the same spatial resolution as LandFlux-EVAL. In addition, the current HOLAPS demonstrator dataset does not include the estimate of LE over snowcovered areas. Therefore, the snow-covered areas of all the products were also masked out based on the MODIS snowcover product.

\subsubsection{Spatial and temporal analysis}

The characteristics of all the datasets were investigated through spatial and temporal analysis. The spatial distri- 

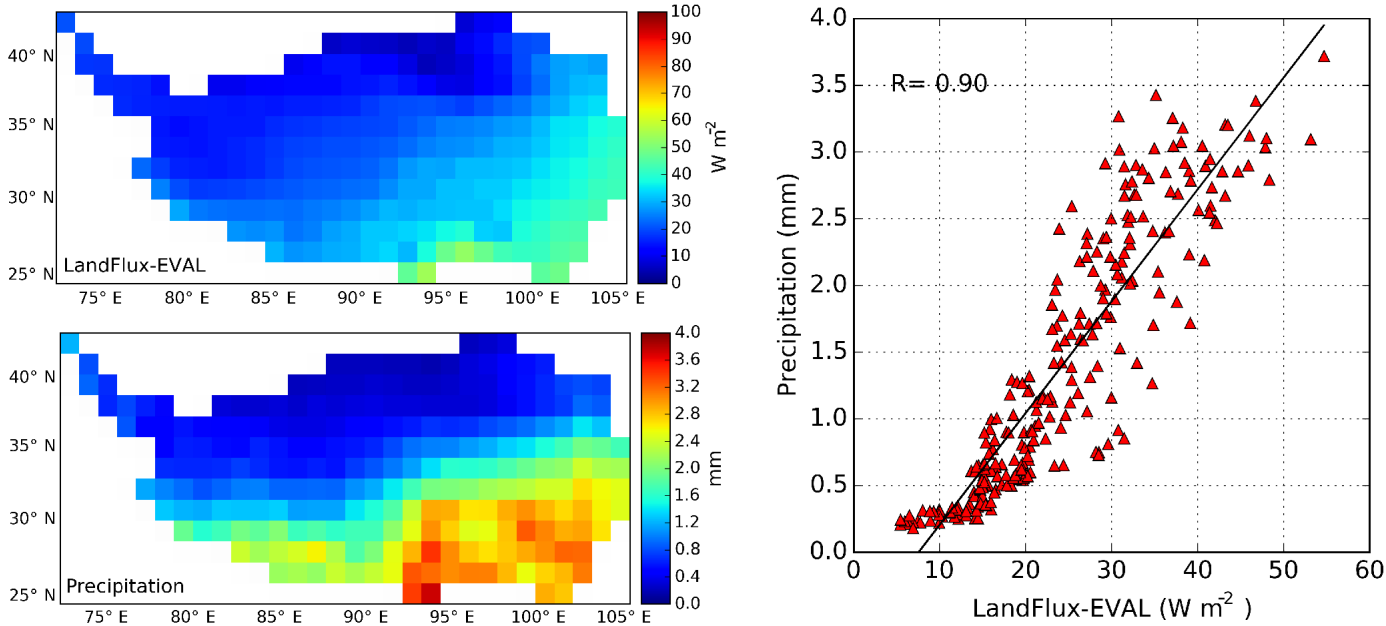

Figure 2. Spatial distribution of annual mean LandFlux-EVAL LE and GPCP precipitation over the TP (left panel). The scatter plots of the comparison between LE and precipitation for all the pixels (right panel).
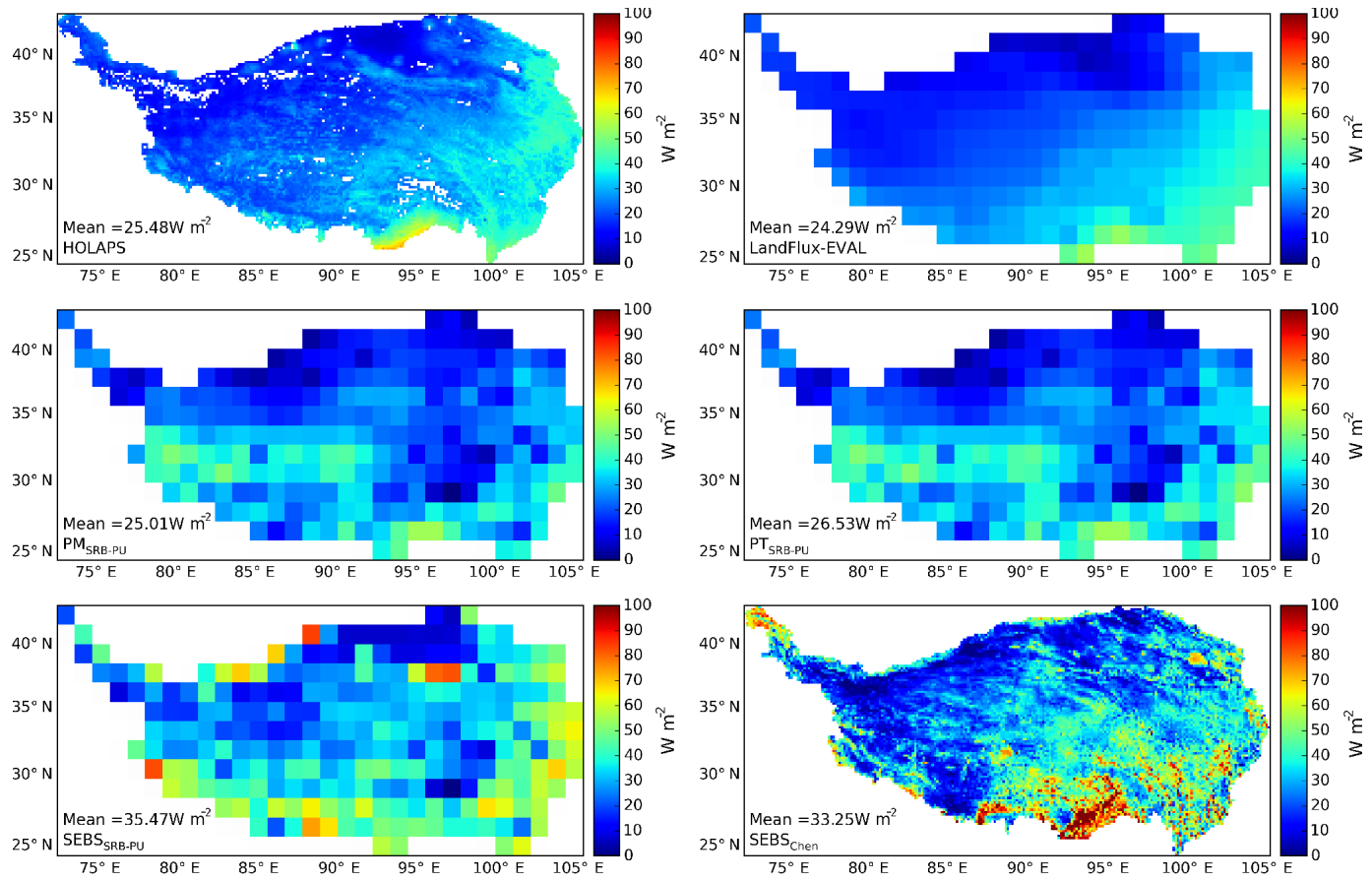

Figure 3. Spatial distribution of annual mean LE for each dataset over the TP.

butions of the seasonal and annual average LE over the TP were analysed, including the identification of patterns such as low and high values, and the investigation of seasonal changes. The four seasons are defined as autumn (September-October-November), winter (DecemberJanuary-February), spring (March-April-May), and summer (June-July-August). The temporal analysis explored the seasonal and annual variation of all the datasets from 2001 to 2005 over the whole TP. In addition, the correlation analysis was conducted to evaluate the impacts of climate (precipi- tation) and surface conditions (normalised difference vegetation index and elevation) on the performance of ET estimation. The relationship between different LE products and the LandFlux-EVAL benchmark product were quantified by using correlation coefficient and root mean square deviation over the whole TP and different sub-regions, which were decided by different intervals of normalised difference vegetation index (NDVI; generated from MODIS), precipitation (Global Precipitation Climatology Project; GPCP), and ele- 

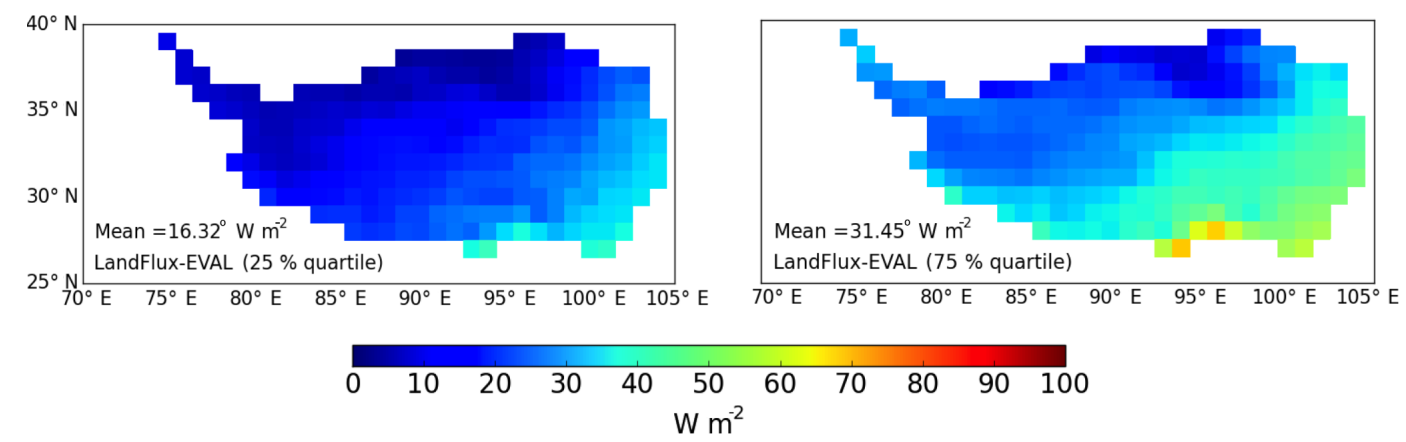

Figure 4. The annual mean spatial patterns of 25 th percentile and 75 th percentile of the LandFlux-EVAL multi-datasets ensemble.

vation (Global Multi-resolution Terrain Elevation Data 2010, GMTED2010).

\section{Results and discussion}

\subsection{Spatial and temporal variability of different $L E$ products}

The spatial distributions of annual mean LandFlux-EVAL and precipitation are shown in Fig. 2. It can be seen that the LE has similar patterns as observation-based precipitation, both decreasing from south-east to north-west over the TP. The comparison of all the pixels shows a very high correlation coefficient of 0.9 between LE and precipitation. Besides precipitation, the radiation is another important driver for LE. Compared to the published studies, the LandFlux-EVAL LE also corresponds well with the merged net radiation and LE datasets, which were developed and validated over the TP by Shi and Liang (2013a, b) and Shi and Liang (2014). The spatial distribution of annual mean net radiation and LE can be found in study of Shi and Liang (2013a) and Shi and Liang (2014). Although the LandFlux-EVAL has not been validated against in situ measurements over the TP, the similar spatial patterns between LE and both observation-based precipitation and validated radiation to some extent demonstrate the validity of LandFlux-EVAL over the TP.

Figure 3 displays the spatial pattern of annual mean values for different LE datasets. Although these LE products have been reported performing well against FLUXNET measurements at point scale, they exhibit differently in terms of spatial pattern over the TP. In general, the LandFlux-EVAL, HO-

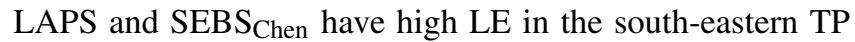
and low LE in the north-western TP, which might be related to the decrease of elevation from north-west to south-east as well as the monsoon climate in the south-eastern TP. The spatial variations of $\mathrm{PT}_{\mathrm{SRB}-\mathrm{PU}}$ and $\mathrm{PM}_{\mathrm{SRB}-\mathrm{PU}}$ are related to the increase of latitude from south to north, while SEBS $_{\text {SRB-PU }}$ has high and low LE in outer and central TP.

Figure 4 further shows the annual mean spatial patterns of 25th percentile and 75th percentile of the LandFlux-EVAL multi-dataset ensemble, which quantifies the uncertainty range of the absolute LE values (interquartile range of the merged synthesis LE products). It can be seen that HOLAPS and most parts of $\mathrm{PT}_{\mathrm{SRB}-\mathrm{PU}}$ and $\mathrm{PM}_{\mathrm{SRB}-\mathrm{PU}}$ are within the interquartile range, while the outer part of SEBS $S_{S R B-P U}$ and southern part of $\mathrm{SEBS}_{\mathrm{Chen}}$ are out of the interquartile range. To make an unbiased comparison between LandFlux-EVAL and other LE datasets, all the datasets were resampled to the same spatial resolution as LandFlux-EVAL and masked out the snow-covered areas. Figure 5 shows the differences in spatial patterns between LandFlux-EVAL and other LE datasets. Overall, the HOLAPS dataset is found to have good agreement with the benchmark product (LandFlux-EVAL) for most parts of TP. The $\mathrm{PT}_{\text {SRB-PU }}$ and $\mathrm{PM}_{\mathrm{SRB}-\mathrm{PU}}$ are found to have positive biases over western TP, and SEBS SRB-PU has $_{\text {a }}$ bias over outer TP, and $\mathrm{SEBS}_{\text {Chen }}$ has bias over southern TP.

Besides the analysis of spatial distribution of annual mean, the seasonal means of each LE dataset are also shown in Fig. 6. It can be seen that all the LE datasets show clear seasonal cycles with the highest values in summer and the lowest values in winter, which might be related to both westerlies and Asian monsoon. Due to the influence of Asian summer monsoon, the highest LE in LandFlux-EVAL is in south-eastern TP and the LE decreases to north-west. The lowest LE appears in northern TP where dry westerlies dominate. Similar patterns are also found in HOLAPS, $\mathrm{PT}_{\mathrm{SRB}-\mathrm{PU}}$, $\mathrm{PM}_{\mathrm{SRB}-\mathrm{PU}}$ and $\mathrm{SEBS}_{\mathrm{Chen}}$. The LE is lower in spring than that in summer in the eastern TP, which relates to the onset of the Asian summer monsoon. All the datasets present very low values during winter due to the cold and dry climate. The seasonal patterns of LandFlux-EVAL are also consistent with the study by You et al. (2014), where the LE was also found to increase from north-west to south-east in all seasons over the TP. Overall, the HOLAPS is most similar to LandFluxEVAL compared to other datasets in terms of spatial distribution and spatial mean values over all seasons.

In addition to the spatial comparisons of annual and seasonal mean values, the time evolution of all datasets is also explored. Figure 7 presents the time series of the area mean LE for different LE datasets, and the inter-quartile range be- 

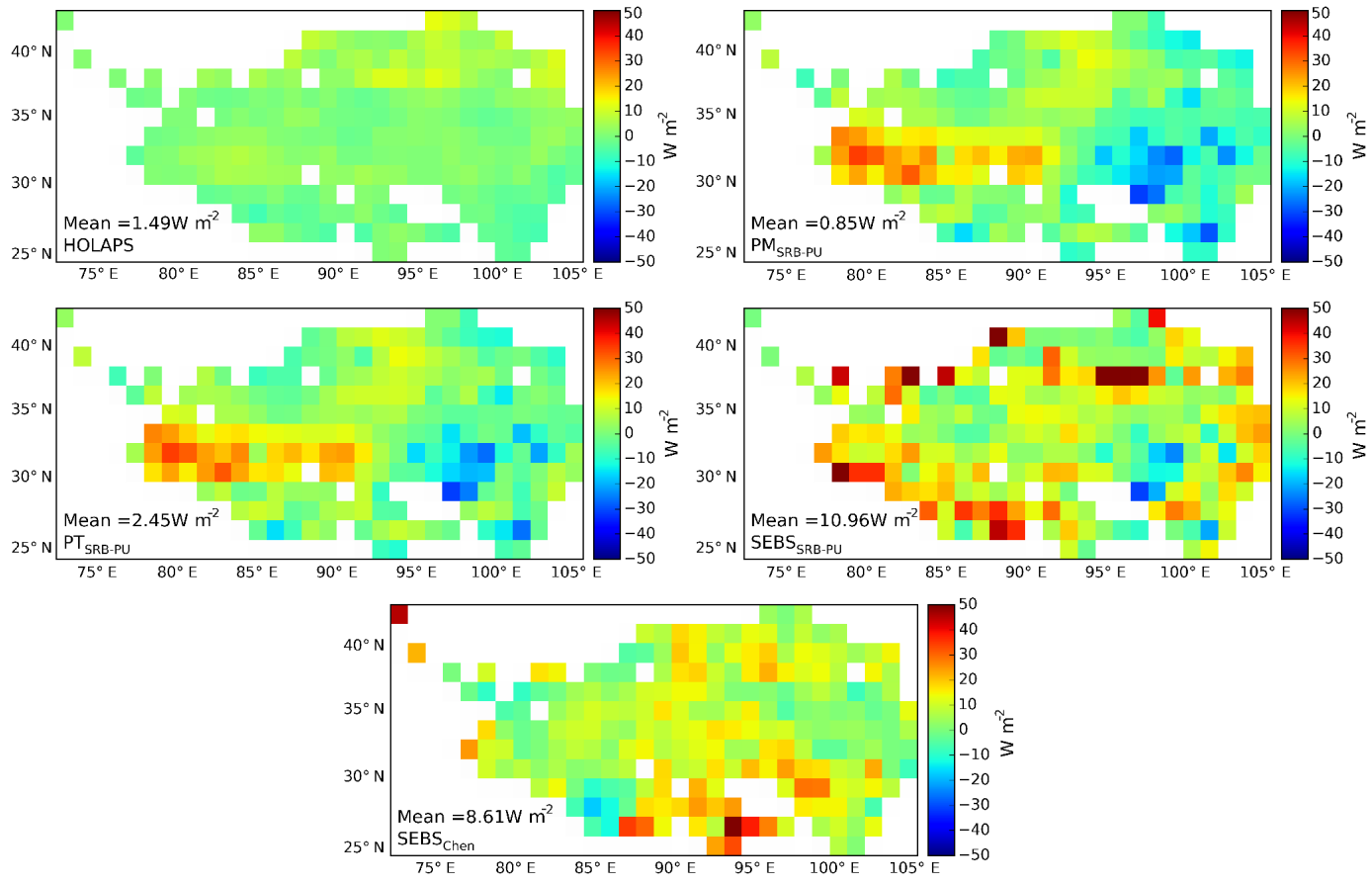

Figure 5. Differences of spatial distribution of annual mean LE between LandFlux-EVAL and other datasets over the TP.

tween 25th percentile and 75th percentile of the LandFluxEVAL ensemble. According to Fig. 7, all products capture well the seasonal variability with minimum LE in the winter and maximum LE in the summer. However, the mean values of different LE products differ substantially. There is a spread of about $35 \mathrm{~W} \mathrm{~m}^{-2}$ at the annual cycle peak. Compared with the other products, the HOLAPS seems to be closer to the LandFlux-EVAL benchmarking product. The SEBS $_{\text {SRB-PU }}$ and SEBS $_{\text {Chen }}$ seem to be more distinctive with LE from most months outside the inter-quartile of LandFluxEVAL ensemble. However, when compared to the climatology calculated from flux tower measurements around the TP the SEBS estimates seem to be close to the flux tower measurements (Chen, 2011). The differences between LandFluxEVAL and SEBS might be caused by the scale mismatch between ground measurement at point scale and the satellite estimate at pixel scale. The mismatch includes the surface heterogeneity (such as topography, land cover types) and atmospheric conditions (such as cloud coverage, altitude variations) (You et al., 2014; Hakuba et al., 2013). Compared to SEBS (Chen, 2011), the LandFlux-EVAL has relative low spatial resolution of $1^{\circ}$, which might be strongly influenced by scale mismatch effects over complex surface and atmospheric conditions in TP. Taking advantage of high temporal resolution of HOLAPS, the temporal variability of the area-averaged LE for 5-day HOLAPS over the 2001-2005 is shown in Fig. 8, where more temporal variations are found compared to monthly temporal variability. Besides, the temporal variation of the averaged LE over the TP has also been compared with precipitation and NDVI, which might regulate the LE. Table 2 shows the statistics of the comparisons. A strong correlation of higher than 0.7 has been found between all LE datasets and NDVI, implying the importance of vegetation on regulating LE over the TP. The highest $R$ value was found between HOLAPS and NDVI. As expected, the LE has strong correlation to precipitation with $R$ value higher than 0.87 for all LE datasets, which is because precipitation is one of the most important drivers for LE. In the next section, the performance of each product will be further discussed based on the comparison results against the LandFlux-EVAL benchmark product.

\subsection{Comparison of LE datasets against LandFlux-EVAL benchmark product}

Figure 9 presents the monthly mean scatter plots of LE between the LandFlux-EVAL benchmark product and other products over the whole TP. The detailed statistics are listed in Table 3. It can be seen that the model performance varies among different LE products with statistical indices values ranging from 0.91 to 0.99 for correlation coefficient $(R)$, and from 2.69 to $17.02 \mathrm{~W} \mathrm{~m}^{-2}$ for root mean square difference (RMSD). Overall, the HOLAPS appears to yield the closest agreement with the LandFlux-EVAL benchmark product, with $R$ higher than 0.99 and RMSD of $2.69 \mathrm{~W} \mathrm{~m}^{-2}$. In addition, the impacts of NDVI, precipitation, and elevation on the estimate of LE are also investigated. Figure 10 shows the comparison results over different NDVI thresholds. Table 4 lists the corresponding statistics includ- 
Table 2. Correlation coefficient $(R)$ between averaged LE and NDVI, precipitation over the TP for the time 2001-2005.

\begin{tabular}{lrrrrrr}
\hline & LandFlux-EVAL & HOLAPS & PM $_{\text {SRB-PU }}$ & PT $_{\text {SRB-PU }}$ & SEBS $_{\text {SRB-PU }}$ & SEBS $_{\text {Chen }}$ \\
\hline$R$ (NDVI) & 0.89 & 0.93 & 0.81 & 0.81 & 0.7 & 0.76 \\
$R$ (precipitation) & 0.98 & 0.96 & 0.96 & 0.96 & 0.87 & 0.94 \\
\hline
\end{tabular}
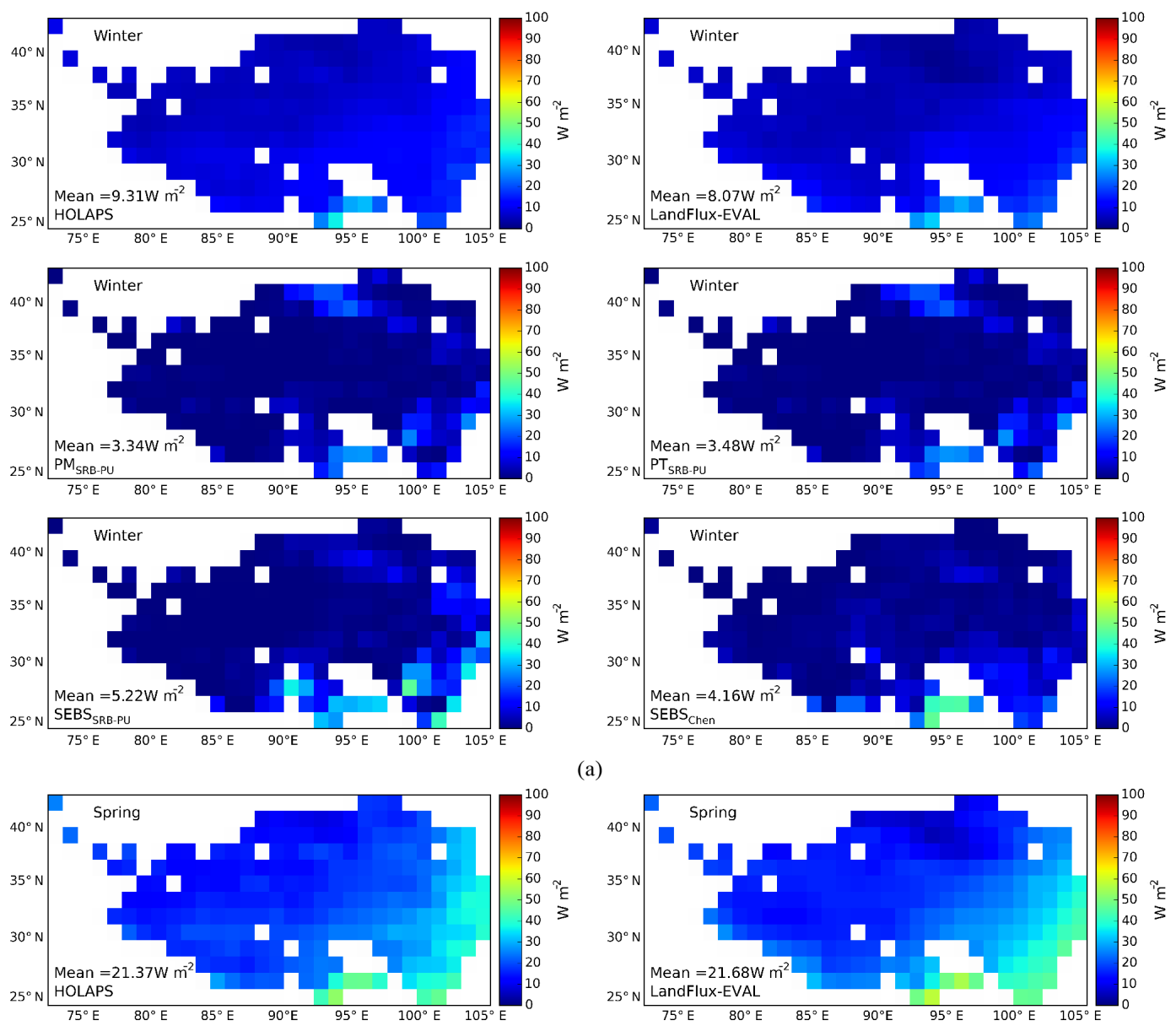

(a)
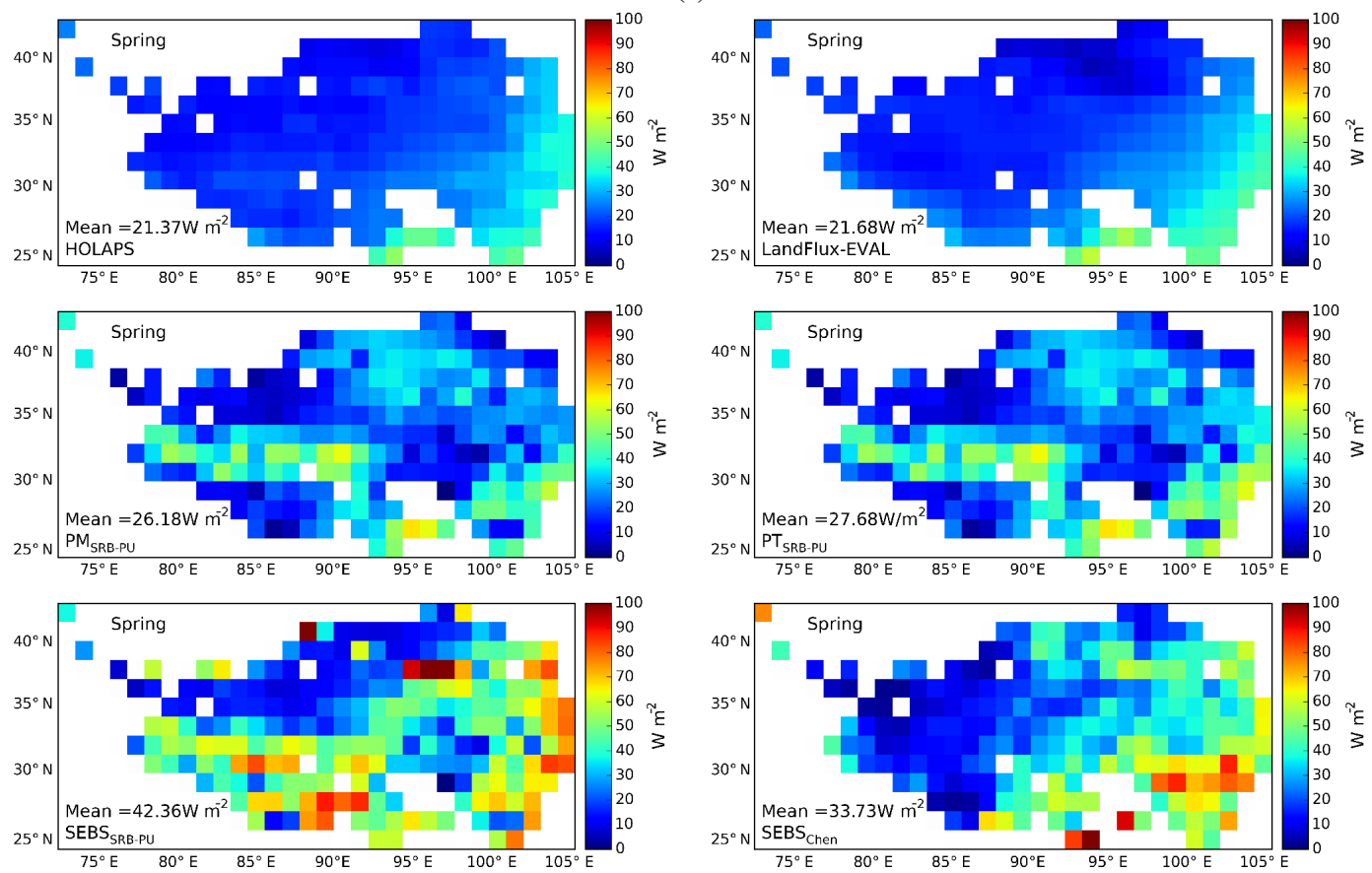

(b)

Figure 6. 

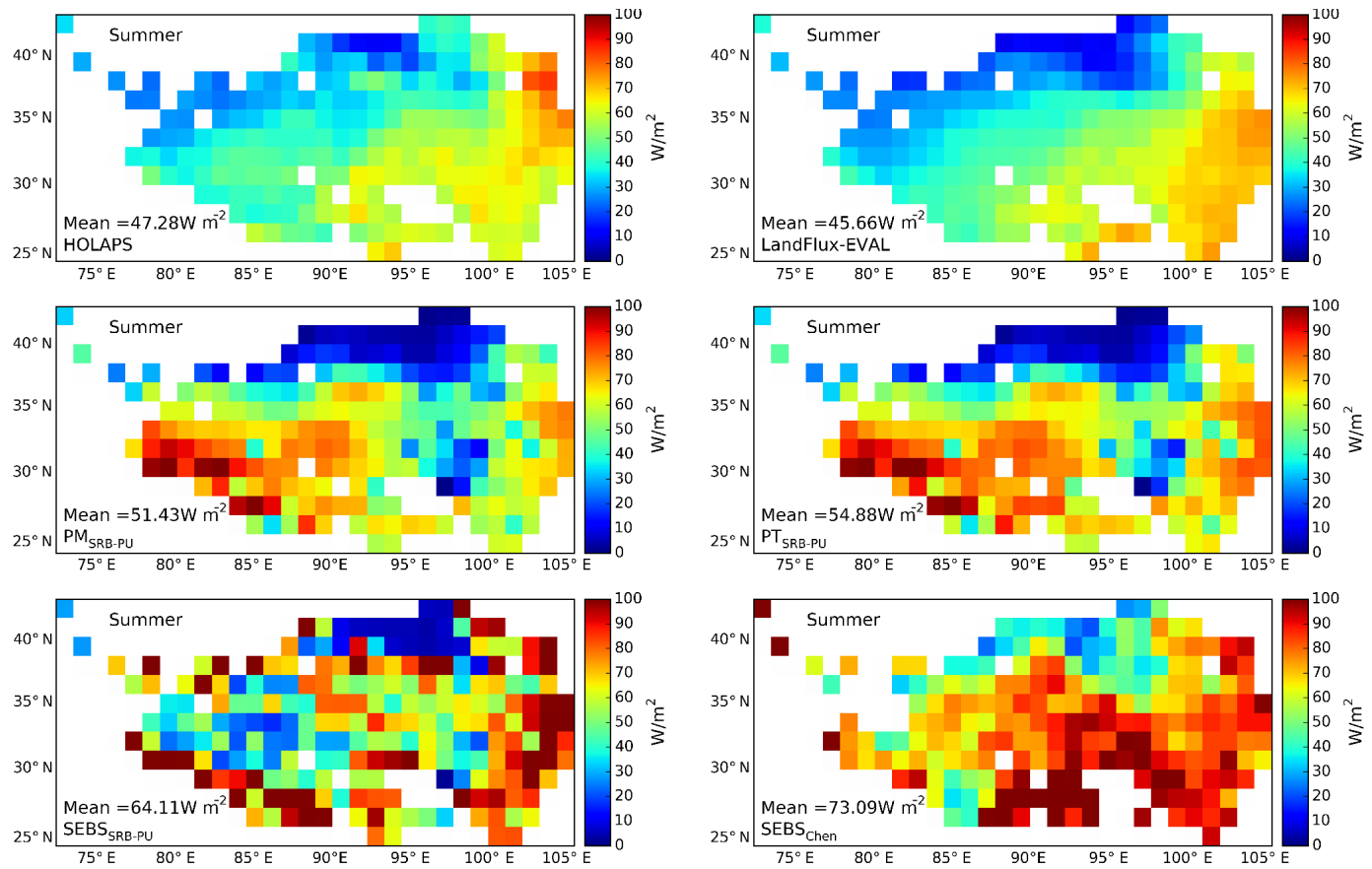

(c)
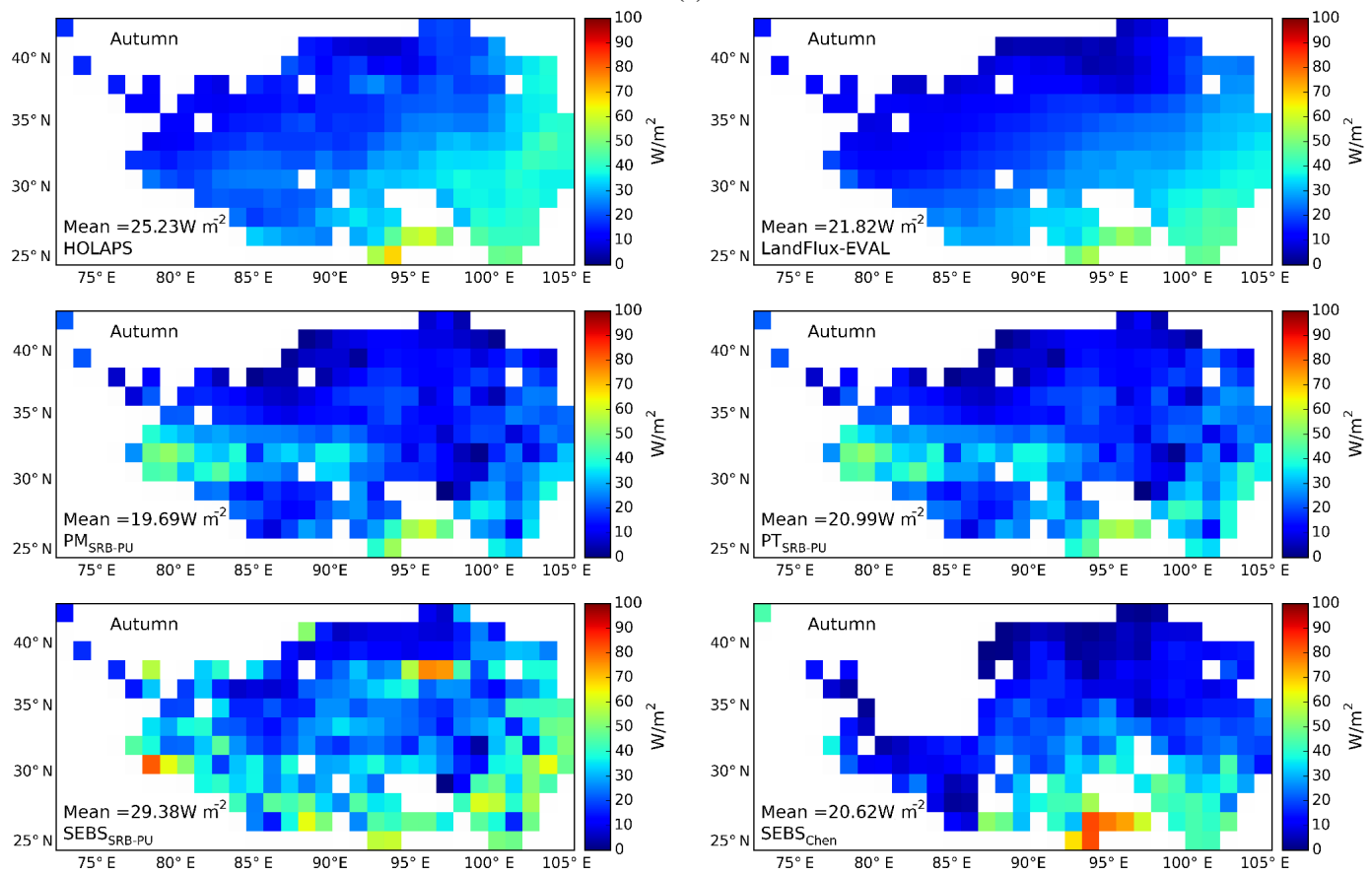

(d)

Figure 6. Spatial distribution of seasonal mean LE for each dataset over the TP. (a) Winter, (b) spring, (c) summer, (d) autumn. 
Table 3. Statistics of the LE comparisons between the LandFlux-EVAL benchmark product and other products over the whole TP.

\begin{tabular}{|c|c|c|c|c|c|c|c|c|c|c|}
\hline & \multicolumn{2}{|c|}{ HOLAPS } & \multicolumn{2}{|c|}{$\mathrm{PM}_{\mathrm{SRB}-\mathrm{PU}}$} & \multicolumn{2}{|c|}{$\mathrm{PT}_{\text {SRB-PU }}$} & \multicolumn{2}{|c|}{ SEBS $_{\text {SRB-PU }}$} & \multicolumn{2}{|c|}{ SEBS $_{\text {Chen }}$} \\
\hline & $R$ & $\begin{array}{r}\text { RMSD } \\
\left(\mathrm{W} \mathrm{m}^{-2}\right)\end{array}$ & $R$ & $\begin{array}{r}\text { RMSD } \\
\left(\mathrm{W} \mathrm{m}^{-2}\right)\end{array}$ & $R$ & $\begin{array}{r}\text { RMSD } \\
\left(\mathrm{W} \mathrm{m}^{-2}\right)\end{array}$ & $R$ & $\begin{array}{r}\text { RMSD } \\
\left(\mathrm{W} \mathrm{m}^{-2}\right)\end{array}$ & $R$ & $\begin{array}{r}\text { RMSD } \\
\left(\mathrm{W} \mathrm{m}^{-2}\right)\end{array}$ \\
\hline Tibetan Plateau & 0.99 & 2.69 & 0.98 & 5.68 & 0.98 & 7.12 & 0.91 & 17.02 & 0.96 & 16.36 \\
\hline
\end{tabular}

Table 4. Statistics of the LE comparisons between the LandFlux-EVAL benchmark product and other products over different NDVI thresholds.

\begin{tabular}{|c|c|c|c|c|c|c|c|c|c|c|}
\hline & \multicolumn{2}{|c|}{ HOLAPS } & \multicolumn{2}{|c|}{$\mathrm{PM}_{\mathrm{SRB}} \mathrm{PU}$} & \multicolumn{2}{|c|}{$\mathrm{PT}_{\text {SRB-PU }}$} & \multicolumn{2}{|c|}{ SEBS $_{\text {SRB-PU }}$} & \multicolumn{2}{|c|}{ SEBS $_{\text {Chen }}$} \\
\hline & $R$ & $\begin{array}{r}\text { RMSD } \\
\left(\mathrm{W} \mathrm{m}^{-2}\right)\end{array}$ & $R$ & $\begin{array}{r}\text { RMSD } \\
\left(\mathrm{W} \mathrm{m}^{-2}\right)\end{array}$ & $R$ & $\begin{array}{r}\text { RMSD } \\
\left(\mathrm{W} \mathrm{m}^{-2}\right)\end{array}$ & $R$ & $\begin{array}{r}\text { RMSD } \\
\left(\mathrm{W} \mathrm{m}^{-2}\right)\end{array}$ & $R$ & $\begin{array}{r}\text { RMSD } \\
\left(\mathrm{W} \mathrm{m}^{-2}\right)\end{array}$ \\
\hline NDVI $\in[0,0.15]$ & 0.99 & 3.27 & 0.96 & 11.42 & 0.96 & 11.89 & 0.84 & 20.93 & 0.95 & 15.38 \\
\hline NDVI $\in(0.15,0.3]$ & 0.98 & 3.59 & 0.95 & 7.46 & 0.96 & 7.09 & 0.88 & 16.42 & 0.94 & 20.09 \\
\hline NDVI $\in(0.3,0.45]$ & 0.98 & 4.08 & 0.99 & 10.88 & 0.99 & 7.4 & 0.94 & 11.43 & 0.92 & 17.6 \\
\hline NDVI $\in(0.45,1]$ & 0.97 & 5.1 & 0.98 & 7.1 & 0.98 & 6.21 & 0.95 & 11.87 & 0.95 & 19.11 \\
\hline
\end{tabular}

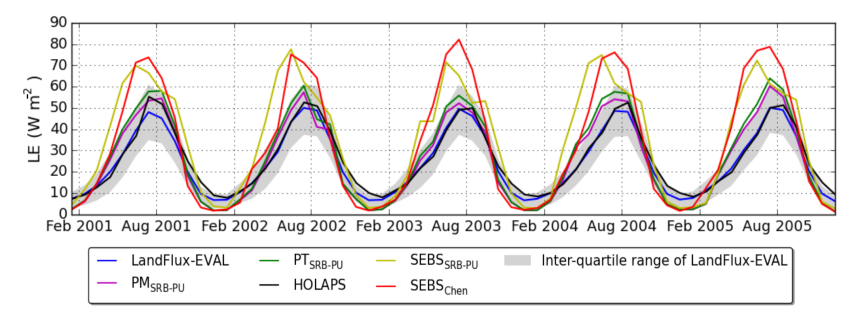

Figure 7. Temporal variability of the area-averaged LE for each dataset over the TP. The grey shadow displays the inter-quartile range between 25 th percentile and 75 th percentile of the LandFluxEVAL multi-datasets ensemble.

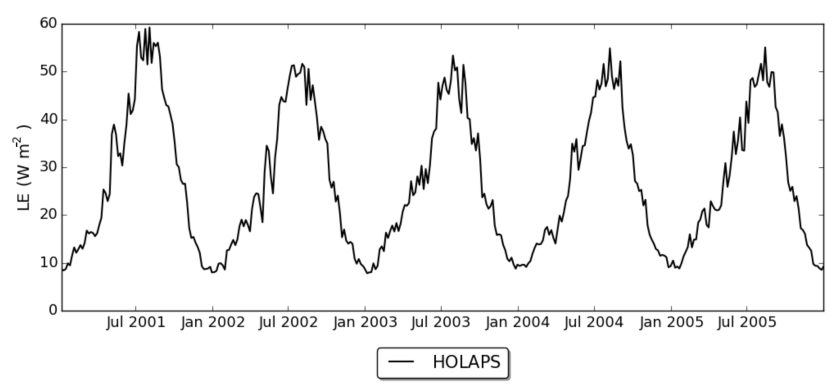

Figure 8. Temporal variability of the area-averaged LE for 5-day HOLAPS over the TP.

ing $R$ and RMSD. The performance of HOLAPS is stable over different NDVI intervals, with RMSD less than $5.1 \mathrm{~W} \mathrm{~m}^{-2}$. PT $\mathrm{PRB}_{\mathrm{SRU}}$ and $\mathrm{PM}_{\mathrm{SRB}}$-PU perform similarly with highest RMSD appearing at the lowest NDVI interval [0, 0.15], and the RMSD of PT SRB-PU decreases with the in-

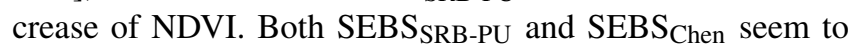
overestimate LE over all NDVI intervals, with RMSD rang-

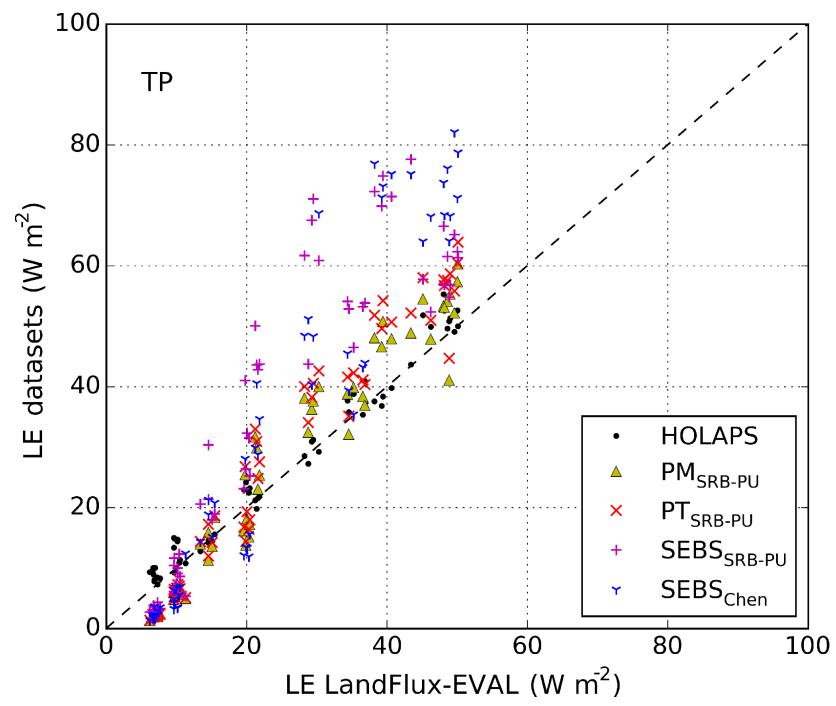

Figure 9. The monthly mean scatter plots of LE between the LandFlux-EVAL benchmark product and other products over the whole TP.

ing from 11.09 to $24.94 \mathrm{~W} \mathrm{~m}^{-2}$. The comparison results over different precipitation thresholds are shown in Fig. 11 and Table 5. Similar to the response to NDVI, the HOLAPS also has stable performances over different precipitation intervals, with RMSD less than $4.91 \mathrm{~W} \mathrm{~m}^{-2}$. PT $\mathrm{SRB}_{\mathrm{SRU}}$ and PMSRB-PU slightly overestimate LE over the areas with low precipitation values $[0,2 \mathrm{~mm}]$, while SEBS $_{\text {SRB-PU }}$ and SEBS $_{\text {Chen }}$ overestimate LE among all precipitation intervals. Figure 12 and Table 6 present the comparison results over the areas with different elevations. In general, the elevation has no strong impacts on the HOLAPS, which has a $R$ value higher than 0.97 and RMSD lower than $5.56 \mathrm{~W} \mathrm{~m}^{-2}$ over all the eleva- 
Table 5. Statistics of the LE comparisons between the LandFlux-EVAL benchmark product and other products over different precipitation thresholds.

\begin{tabular}{|c|c|c|c|c|c|c|c|c|c|c|}
\hline & \multicolumn{2}{|c|}{ HOLAPS } & \multicolumn{2}{|c|}{$\mathrm{PM}_{\mathrm{SRB}-\mathrm{PU}}$} & \multicolumn{2}{|c|}{$\mathrm{PT}_{\mathrm{SRB}-\mathrm{PU}}$} & \multicolumn{2}{|c|}{ SEBSSRB-PU $_{\text {SR }}$} & \multicolumn{2}{|c|}{ SEBS $_{\text {Chen }}$} \\
\hline & $R$ & $\begin{array}{r}\text { RMSD } \\
\left(\mathrm{W} \mathrm{m}^{-2}\right)\end{array}$ & $R$ & $\begin{array}{r}\text { RMSD } \\
\left(\mathrm{W} \mathrm{m}^{-2}\right)\end{array}$ & $R$ & $\begin{array}{r}\text { RMSD } \\
\left(\mathrm{W} \mathrm{m}^{-2}\right)\end{array}$ & $R$ & $\begin{array}{r}\text { RMSD } \\
\left(\mathrm{W} \mathrm{m}^{-2}\right)\end{array}$ & $R$ & $\begin{array}{r}\text { RMSD } \\
\left(\mathrm{W} \mathrm{m}^{-2}\right)\end{array}$ \\
\hline Precipitation $\in[0,1]$ & 0.99 & 3.97 & 0.95 & 8.08 & 0.95 & 8.56 & 0.86 & 19.5 & 0.94 & 15.96 \\
\hline Precipitation $\in(1,2]$ & 0.98 & 3.48 & 0.97 & 11.05 & 0.98 & 13.52 & 0.83 & 20 & 0.95 & 17.9 \\
\hline Precipitation $\in(2,3]$ & 0.99 & 3.36 & 0.98 & 9.21 & 0.98 & 7.45 & 0.96 & 14.89 & 0.96 & 16.26 \\
\hline Precipitation $\in(3,4]$ & 0.97 & 4.91 & 0.95 & 7.82 & 0.95 & 6.68 & 0.89 & 11.09 & 0.94 & 24.94 \\
\hline
\end{tabular}
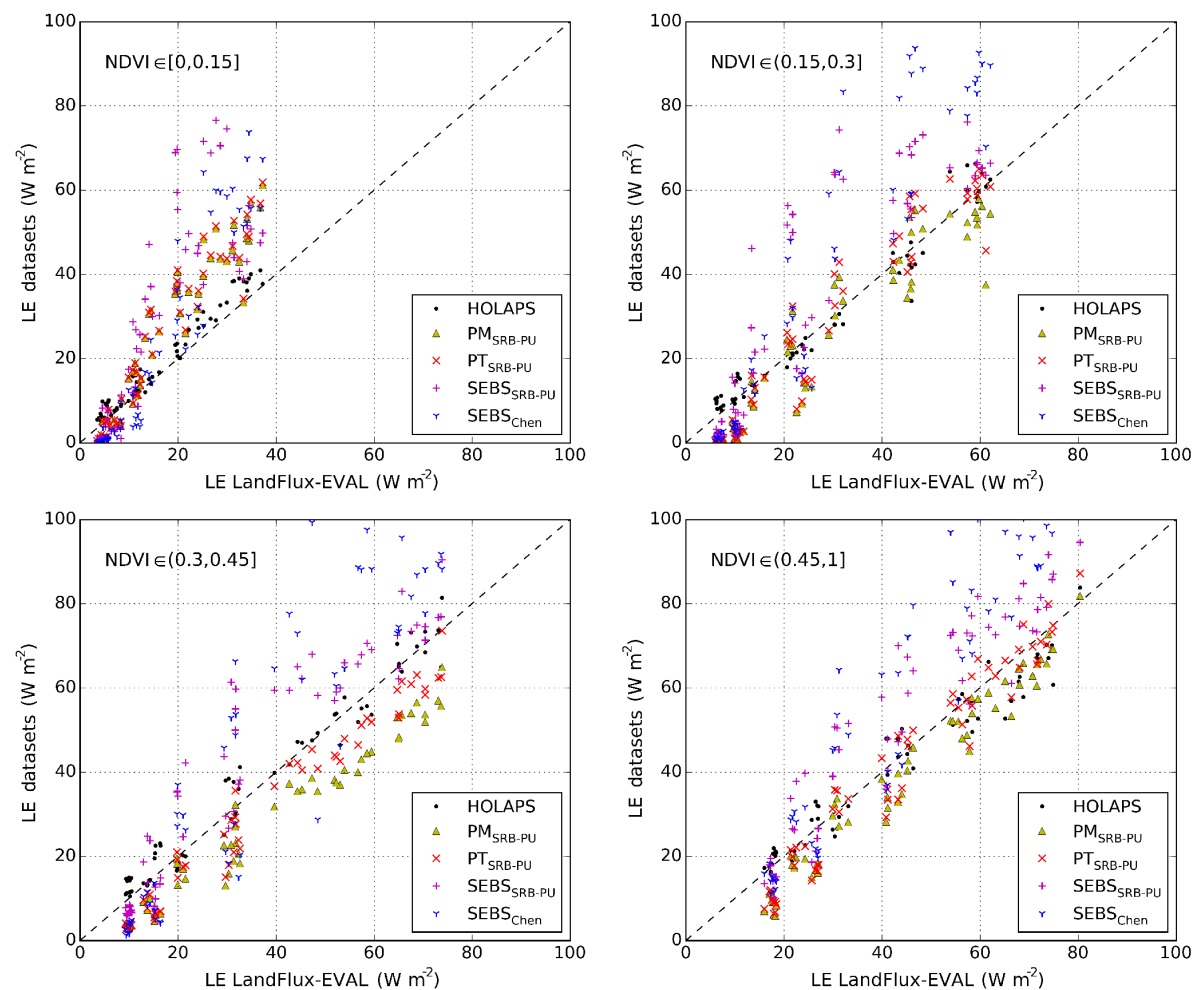

Figure 10. The monthly mean scatter plots of LE between the LandFlux-EVAL benchmark product and other products over different NDVI thresholds.

tion intervals. $\mathrm{PT}_{\mathrm{SRB}} \mathrm{PU}$ and $\mathrm{PM}_{\mathrm{SRB}}$-PU have similar performance, with overestimation of LE in areas with high elevation $[5000,6000 \mathrm{~m}]$. Relatively low $R$ values for $\mathrm{PT}_{\mathrm{SRB}} \mathrm{PU}$ and $\mathrm{PM}_{\mathrm{SRB}-\mathrm{PU}}$ are also found over areas with low elevations [1000, $3000 \mathrm{~m}]$. SEBS $_{\text {SRB-PU }}$ and SEBS $_{\text {Chen }}$ both overestimate LE over all elevation intervals. Overall, the HOLAPS LE has stable performance over different NDVI, precipitation, and elevation values. $\mathrm{PT}_{\mathrm{SRB}-\mathrm{PU}}$ and $\mathrm{PM}_{\mathrm{SRB}-\mathrm{PU}}$ have very similar performance. The SEBS $\mathrm{SRB}$-PU has the highest uncertainty over areas with low NDVI and precipitation and high elevation, while the highest uncertainty for $\mathrm{SEBS}_{\mathrm{Chen}}$ occurs in areas with high NDVI and precipitation and low elevation.

\subsection{Discussion on the different performance of the LE datasets over TP}

The spatial and temporal inter-comparisons of different global LE datasets over the TP suggest that there are large differences among different datasets. The LandFluxEVAL benchmark product was found to agree well with observation-based precipitation, in situ measurementsvalidated radiation (Shi and Liang, 2013a), and in situ measurements-validated LE product (Shi and Liang, 2014). From this point of view, it can be served as the reference dataset. The HOLAPS is found to agree temporally and spatially well with LandFlux-EVAL benchmark product. The PT $\mathrm{SRB}_{\mathrm{SRU}}$ and $\mathrm{PM}_{\mathrm{SRB}-\mathrm{PU}}$ have similar performance and are within the uncertainty range provided by 

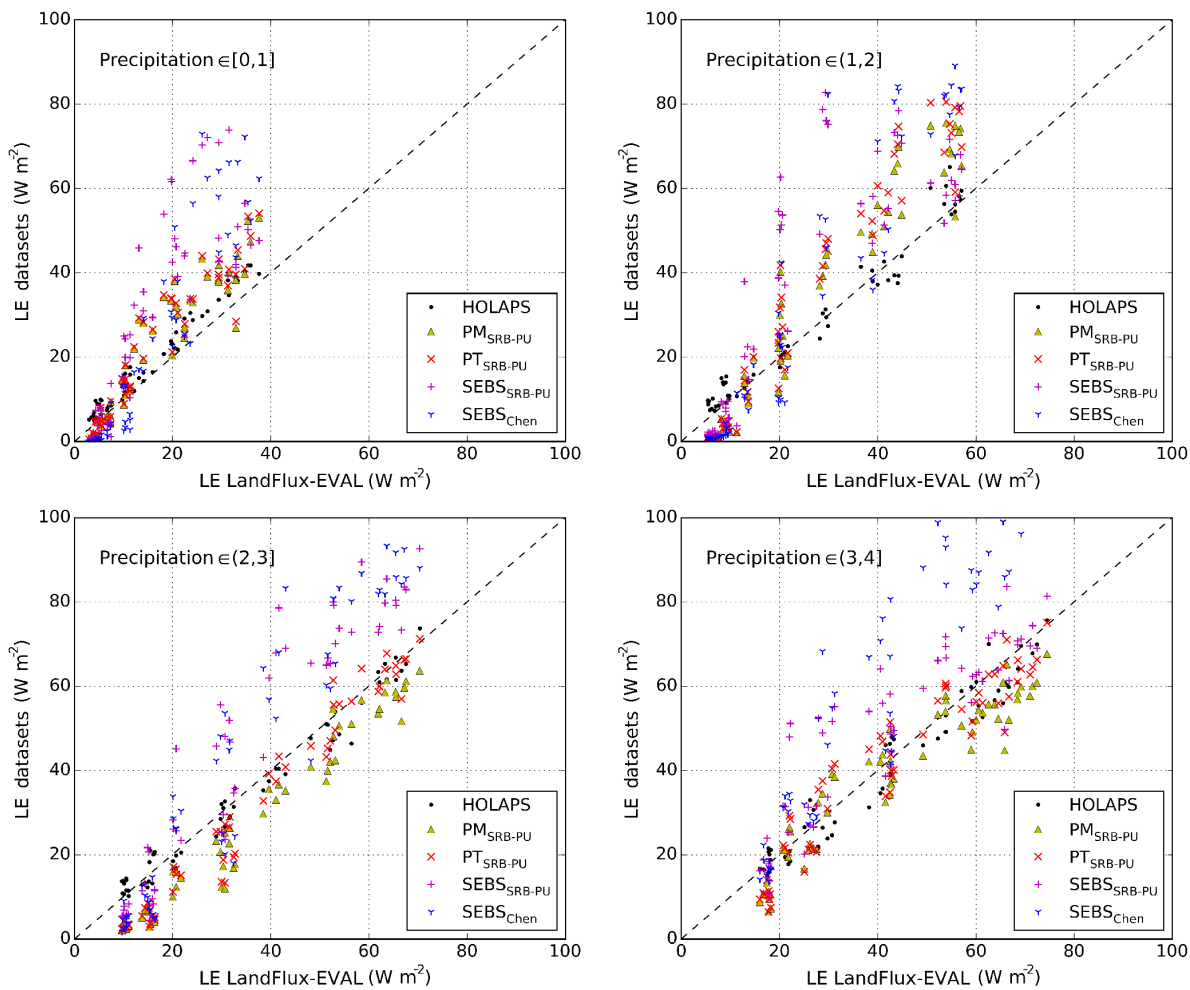

Figure 11. The monthly mean scatter plots of LE between the LandFlux-EVAL benchmark product and other products over different precipitation thresholds.
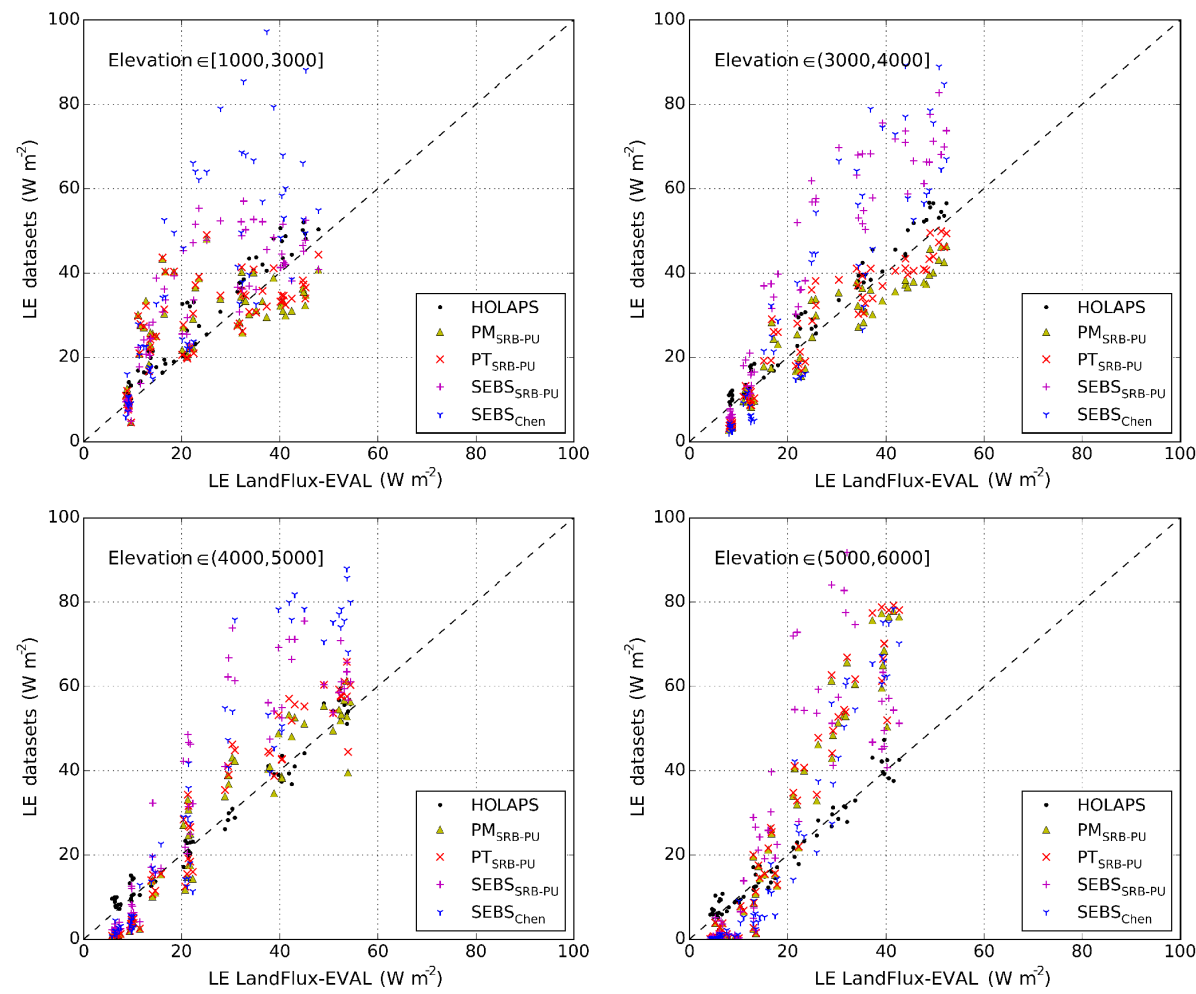

Figure 12. The monthly mean scatter plots of LE between the LandFlux-EVAL benchmark product and other products over different elevation thresholds. 
Table 6. Statistics of the LE comparisons between the LandFlux-EVAL benchmark product and other products over different elevation thresholds.

\begin{tabular}{|c|c|c|c|c|c|c|c|c|c|c|}
\hline & \multicolumn{2}{|c|}{ HOLAPS } & \multicolumn{2}{|c|}{$\mathrm{PM}_{\text {SRB-PU }}$} & \multicolumn{2}{|c|}{$\mathrm{PT}_{\text {SRB-PU }}$} & \multicolumn{2}{|c|}{ SEBS $_{\text {SRB-PU }}$} & \multicolumn{2}{|c|}{ SEBS $_{\text {Chen }}$} \\
\hline & $R$ & $\begin{array}{r}\text { RMSD } \\
\left(\mathrm{W} \mathrm{m}^{-2}\right)\end{array}$ & $R$ & $\begin{array}{r}\text { RMSD } \\
\left(\mathrm{W} \mathrm{m}^{-2}\right)\end{array}$ & $R$ & $\begin{array}{r}\text { RMSD } \\
\left(\mathrm{W} \mathrm{m}^{-2}\right)\end{array}$ & $R$ & $\begin{array}{r}\text { RMSD } \\
\left(\mathrm{W} \mathrm{m}^{-2}\right)\end{array}$ & $R$ & $\begin{array}{r}\text { RMSD } \\
\left(\mathrm{W} \mathrm{m}^{-2}\right)\end{array}$ \\
\hline Elevation $\in[1000,3000]$ & 0.97 & 5.56 & 0.64 & 10.24 & 0.69 & 9.94 & 0.79 & 12.92 & 0.76 & 22.53 \\
\hline Elevation $\in(3000,4000]$ & 0.99 & 4.06 & 0.94 & 5.71 & 0.95 & 5.05 & 0.93 & 20.02 & 0.91 & 17.77 \\
\hline Elevation $\in(4000,5000]$ & 0.99 & 2.72 & 0.96 & 6.4 & 0.97 & 7.56 & 0.9 & 15.93 & 0.95 & 17.76 \\
\hline Elevation $\in(5000,6000]$ & 0.98 & 2.45 & 0.97 & 16.82 & 0.97 & 17.6 & 0.83 & 21.39 & 0.96 & 15.24 \\
\hline
\end{tabular}

LandFlux-EVAL product. Despite relying on the same forcing dataset, $\mathrm{SEBS}_{\mathrm{SRB}-\mathrm{PU}}$ performs differently from $\mathrm{PT}_{\mathrm{SRB}} \mathrm{PU}$ and $\mathrm{PM}_{\mathrm{SRB}-\mathrm{PU}}$, which is driven by the differences in the models. Since all these datasets rely on the same radiation forcing, the overestimation is due to the high sensitivity to the parameterisation of resistances. Therefore, examination of the differences between the models especially the calculated resistances still needs to be conducted in future work. In addition, for the same model, different forcing data lead to different results (SEBS $S_{\text {SRB-PU }}$ and SEBS $_{\text {Chen }}$ ). The overestimation in both SEBS datasets suggests the high sensitivity of LE to the calculated resistances, and the different spatial patterns and magnitude between the two SEBS datasets are likely due to the different forcing datasets. These results suggest that model and forcing are equally critical for the estimation of ET. Future studies should be focused on the development of a high quality forcing dataset, and the exploration of the sensitivity of each model to its forcing. This type of research could be facilitated by the HOLAPS framework. Because the components in HOLAPS are coupled through well-defined interfaces, which allows for the integration of different models for estimation of ET while building on the general HOLAPS infrastructure for providing the consistent forcing data. Overall, the results presented here suggest that the validation and inter-comparison are essential before applying the global LE datasets for regional applications, especially for the areas with sparse in situ measurements such as TP. The high spatial and temporal resolution HOLAPS demonstrator dataset provides a potential LE product for hydrological applications over TP. However, the current HOLAPS demonstrator dataset does not consider the ET over snow-covered areas. The parameterisation scheme of ET over snow-covered areas will be added in the HOLAPS framework to generate the next version of the HOLAPS dataset.

\section{Conclusions}

This study provides a first comprehensive inter-comparison of existing LE products over the TP for the period 20012005. The results of the study can be summarised as follows:

1. The existing global LE products show substantial differences in spatial and temporal patterns over the TP, although all these products have been found to agree well with FLUXNET measurements in different climate conditions.

2. The LandFlux-EVAL benchmark product as well as the HOLAPS LE show very similar spatial patterns, both with LE increasing from north-west to south-east. The other LE products $\left(\mathrm{SEBS}_{\mathrm{SRB}-\mathrm{PU}}, \mathrm{SEBS}_{\mathrm{Chen}}, \mathrm{PT}_{\mathrm{SRB}-\mathrm{PU}}\right.$ and $\mathrm{PM}_{\mathrm{SRB}-\mathrm{PU}}$ ) display different spatial patterns compared to LandFlux-EVAL LE. The differences between

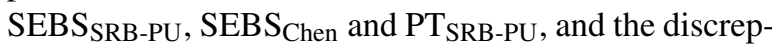
ancies between SEBS $_{\mathrm{SRB}-\mathrm{PU}}$ and $\mathrm{SEBS}_{\mathrm{Chen}}$ indicate the equal importance of model structure and forcing data. Nevertheless, all products capture well the seasonal variability with maximum $L E$ in the summer and minimum LE in the winter. The HOLAPS LE was found to agree best with LandFlux-EVAL LE.

3. Further comparison against LandFlux-EVAL benchmark dataset over the whole TP and sub-regions that are decided by different intervals of NDVI, precipitation, and elevation reveals that climate and surface conditions have impacts on the performances of SEBS $S_{\mathrm{SRB}-\mathrm{PU}}$, SEBS $_{\text {Chen }}$, PT $_{\text {SRB-PU, }}$, and PM SRB-PU, which implying $_{\text {S }}$ that the systematic deviations between these datasets are partly due to the impacts of different climate and surface conditions. Note that the HOLAPS LE product is insensitive to different climate and surface conditions over the TP, compared to other LE datasets.

Overall, there are still large uncertainties in the current global LE dataset over the TP. In order to accurately estimate LE over the TP, model calibration ad development of high accuracy forcing dataset are still needed. There is therefore a strong need for appropriate in situ flux measurements as well as other hydrological data such as, e.g. runoff measurements. 


\section{Data availability}

This study uses the LandFlux-EVAL merged benchmark synthesis products of ETH Zurich produced under the aegis of the GEWEX and ILEAPS projects (http://www.iac.ethz.ch/group/land-climate-dynamics/ research/landflux-eval.html). The SEBS $S_{\text {SRB-PU, }}$ PT SRB-PU, and PMSRB-PU LE products were obtained from the Princeton University Terrestrial Hydrology Research Group (http://hydrology.princeton.edu/data.php). The HOLAPS, MODIS NDVI and snow cover, GPCP precipitation, and GMTED2010 elevation data are obtained from the Integrated Climate Data Center (ICDC, http://icdc.zmaw.de). The SEBS $_{\text {Chen }}$ data are available on request via email (x.chen@utwente.nl).

Acknowledgements. This research was supported by the Cluster of Excellence CliSAP (EXC177), University of Hamburg, funded through the German Science Foundation (DFG), and the MPG-CAS postdoc fellowship. The authors would like to thank Stefan Hagemann for reviewing the first version of the manuscript. The authors are also very grateful to the editor and six anonymous reviewers for their valuable comments that helped improve the manuscript.

The article processing charges for this open-access publication were covered by the Max Planck Society.

Edited by: L. Samaniego

Reviewed by: six anonymous referees

\section{References}

Anderson, M. C., Norman, J. M., Mecikalski, J. R., Otkin, J. A., and Kustas, W. P.: A climatological study of evapotranspiration and moisture stress across the continental United States based on thermal remote sensing: 1. Model formulation, J. Geophys. Res.Atmos., 112, D10117, doi:10.1029/2006JD007506, 2007.

Anderson, M. C., Kustas, W. P., Norman, J. M., Hain, C. R., Mecikalski, J. R., Schultz, L., González-Dugo, M. P., Cammalleri, C., d'Urso, G., Pimstein, A., and Gao, F.: Mapping daily evapotranspiration at field to continental scales using geostationary and polar orbiting satellite imagery, Hydrol. Earth Syst. Sci., 15, 223-239, doi:10.5194/hess-15-223-2011, 2011.

Bastiaanssen, W., Menenti, M., Feddes, R., and Holtslag, A.: A remote sensing surface energy balance algorithm for land (SEBAL), 1. Formulation, J. Hydrol., 212, 198-212, 1998.

Chen, X.: Observations analysis of energy exchange between the land surface and atmosphere and its application to parameterization method over the Tibetan Plateau, PhD, Institute of Tibetan Plateau Research, Institute of Tibetan Plateau Research, Chinese Academy of Sciences, 2011.

Chen, X., Su, Z., Ma, Y., Yang, K., and Wang, B.: Estimation of surface energy fluxes under complex terrain of Mt. Qomolangma over the Tibetan Plateau, Hydrol. Earth Syst. Sci., 17, 16071618, doi:10.5194/hess-17-1607-2013, 2013a.
Chen, X., Su, Z., Ma, Y., Yang, K., Wen, J., and Zhang, Y.: An improvement of roughness height parameterization of the Surface Energy Balance System (SEBS) over the Tibetan Plateau, J. Appl. Meteorol. Climatol., 52, 607-622, 2013 b.

Chen, X., Su, Z., Ma, Y., Liu, S., Yu, Q., and Xu, Z.: Development of a 10-year (2001-2010) $0.1^{\circ}$ data set of land-surface energy balance for mainland China, Atmos. Chem. Phys., 14, 1309713117, doi:10.5194/acp-14-13097-2014, 2014.

Cui, X. and Graf, H.-F.: Recent land cover changes on the Tibetan Plateau: a review, Climatic Change, 94, 47-61, 2009.

Duan, A. and Wu, G.: Role of the Tibetan Plateau thermal forcing in the summer climate patterns over subtropical Asia, Clim. Dynam., 24, 793-807, 2005.

Ershadi, A., McCabe, M. F., Evans, J. P., Chaney, N. W., and Wood, E. F.: Multi-site evaluation of terrestrial evaporation models using FLUXNET data, Agricult. Forest Meteorol., 187, 46-61, 2014.

Fisher, J. B., Tu, K. P., and Baldocchi, D. D.: Global estimates of the land-atmosphere water flux based on monthly AVHRR and ISLSCP-II data, validated at 16 FLUXNET sites, Remote Sens. Environ., 112, 901-919, 2008.

Frauenfeld, O. W., Zhang, T., and Serreze, M. C.: Climate change and variability using European Centre for MediumRange Weather Forecasts reanalysis (ERA-40) temperatures on the Tibetan Plateau, J. Geophys. Res.-Atmos., 110, D02101, doi:10.1029/2004JD005230, 2005.

Gerken, T., Babel, W., Hoffmann, A., Biermann, T., Herzog, M., Friend, A. D., Li, M., Ma, Y., Foken, T., and Graf, H.-F.: Turbulent flux modelling with a simple 2-layer soil model and extrapolated surface temperature applied at Nam Co Lake basin on the Tibetan Plateau, Hydrol. Earth Syst. Sci., 16, 1095-1110, doi:10.5194/hess-16-1095-2012, 2012.

Hakuba, M. Z., Folini, D., Sanchez-Lorenzo, A., and Wild, M.: Spatial representativeness of ground-based solar radiation measurements, J. Geophys. Res.-Atmos., 118, 8585-8597, 2013.

Immerzeel, W. W., Van Beek, L. P., and Bierkens, M. F.: Climate change will affect the Asian water towers, Science, 328, 1382 1385, 2010.

Jiménez, C., Prigent, C., Mueller, B., Seneviratne, S. I., McCabe, M. F., Wood, E. F., Rossow, W. B., Balsamo, G., Betts, A. K., Dirmeyer, P. A., Fisher, J. B., Jung, M., Kanamitsu, M., Reichle, R. H., Reichstein, M., Rodell, M., Sheffield, J., Tu, K., and Wang, K.: Global intercomparison of 12 land surface heat flux estimates, J. Geophys. Res.-Atmos., 116, D02102, doi:10.1029/2010JD014545, 2011.

Jung, M., Reichstein, M., Ciais, P., Seneviratne, S. I., Sheffield, J., Goulden, M. L., Bonan, G., Cescatti, A., Chen, J., de Jeu, R., Dolman, A. J., Eugster, W., Gerten, D., Gianelle, D., Gobron, N., Heinke, J., Kimball, J., Law, B. E., Montagnani, L., Mu, Q., Mueller, B., Oleson, K., Papale, D., Richardson, A. D., Roupsard, O., Running, S., Tomelleri, E., Viovy, N., Weber, U., Williams, C., Wood, E., Zaehle, S., and Zhang, K.: Recent decline in the global land evapotranspiration trend due to limited moisture supply, Nature, 467, 951-954, 2010.

Kalma, J., McVicar, T., and McCabe, M.: Estimating Land Surface Evaporation: A Review of Methods Using Remotely Sensed Surface Temperature Data, Surv. Geophys., 29, 421-469, 2008. 
Lau, K., Kim, M., and Kim, K.: Asian summer monsoon anomalies induced by aerosol direct forcing: the role of the Tibetan Plateau, Clim. Dynam., 26, 855-864, 2006.

Lee, J. H., Timmermans, J., Su, Z., and Mancini, M.: Calibration of aerodynamic roughness over the Tibetan Plateau with Ensemble Kalman Filter analysed heat flux, Hydrol. Earth Syst. Sci., 16, 4291-4302, doi:10.5194/hess-16-4291-2012, 2012.

Loew, A., Peng, J., and Borsche, M.: High-resolution land surface fluxes from satellite and reanalysis data (HOLAPS v1.0): evaluation and uncertainty assessment, Geosci. Model Dev., 9, 24992532, doi:10.5194/gmd-9-2499-2016, 2016.

Ma, Y., Ishikawa, H., Tsukamoto, O., Menenti, M., Su, Z., Yao, T., Koike, T., and Yasunari, T.: Regionalization of surface fluxes over heterogeneous landscape of the Tibetan Plateau by using satellite remote sensing data, J. Meteorol. Soc. Jpn., 81, 277293, 2003.

Ma, Y., Zhong, L., Su, Z., Ishikawa, H., Menenti, M., and Koike, T.: Determination of regional distributions and seasonal variations of land surface heat fluxes from Landsat-7 Enhanced Thematic Mapper data over the central Tibetan Plateau area, J. Geophys. Res.-Atmos., 111, D10305, doi:10.1029/2005JD006742, 2006.

Ma, Y., Kang, S., Zhu, L., Xu, B., Tian, L., and Yao, T.: Roof of the world: Tibetan Observation and Research Platform, B. Am. Meteorol. Soc., 89, 1487-1492, 2008.

Ma, Y., Zhong, L., Wang, B., Ma, W., Chen, X., and Li, M.: Determination of land surface heat fluxes over heterogeneous landscape of the Tibetan Plateau by using the MODIS and in situ data, Atmos. Chem. Phys., 11, 10461-10469, doi:10.5194/acp11-10461-2011, 2011.

Ma, Y., Zhu, Z., Zhong, L., Wang, B., Han, C., Wang, Z., Wang, Y., Lu, L., Amatya, P. M., Ma, W., and Hu, Z.: Combining MODIS, AVHRR and in situ data for evapotranspiration estimation over heterogeneous landscape of the Tibetan Plateau, Atmos. Chem. Phys., 14, 1507-1515, doi:10.5194/acp-14-1507-2014, 2014.

McCabe, M. F., Ershadi, A., Jimenez, C., Miralles, D. G., Michel, D., and Wood, E. F.: The GEWEX LandFlux project: evaluation of model evaporation using tower-based and globally gridded forcing data, Geosci. Model Dev., 9, 283-305, doi:10.5194/gmd9-283-2016, 2016.

Michel, D., Jiménez, C., Miralles, D. G., Jung, M., Hirschi, M., Ershadi, A., Martens, B., McCabe, M. F., Fisher, J. B., Mu, Q., Seneviratne, S. I., Wood, E. F., and Fernández-Prieto, D.: The WACMOS-ET project - Part 1: Tower-scale evaluation of four remote-sensing-based evapotranspiration algorithms, Hydrol. Earth Syst. Sci., 20, 803-822, doi:10.5194/hess-20-8032016, 2016.

Miralles, D. G., Holmes, T. R. H., De Jeu, R. A. M., Gash, J. H., Meesters, A. G. C. A., and Dolman, A. J.: Global land-surface evaporation estimated from satellite-based observations, Hydrol. Earth Syst. Sci., 15, 453-469, doi:10.5194/hess-15-453-2011, 2011

Miralles, D. G., van den Berg, M. J., Gash, J. H., Parinussa, R. M., de Jeu, R. A. M., Beck, H. E., Holmes, T. R. H., Jiménez, C., Verhoest, N. E. C., Dorigo, W. A., Teuling, A. J., and Johannes Dolman, A.: El Niño-La Niña cycle and recent trends in continental evaporation, Nat. Clim. Change, 4, 122-126, 2014.

Miralles, D. G., Jiménez, C., Jung, M., Michel, D., Ershadi, A., McCabe, M. F., Hirschi, M., Martens, B., Dolman, A. J., Fisher, J. B., Mu, Q., Seneviratne, S. I., Wood, E. F., and Fernández-Prieto,
D.: The WACMOS-ET project - Part 2: Evaluation of global terrestrial evaporation data sets, Hydrol. Earth Syst. Sci., 20, 823842, doi:10.5194/hess-20-823-2016, 2016.

Monin, A. and Obukhov, A.: Basic laws of turbulent mixing in the surface layer of the atmosphere, Tr. Akad. Nauk SSSR Geophiz. Inst., 24, 163-187, 1954.

Mu, Q., Heinsch, F. A., Zhao, M., and Running, S. W.: Development of a global evapotranspiration algorithm based on MODIS and global meteorology data, Remote Sens. Environ., 111, 519-536, 2007.

Mu, Q., Zhao, M., and Running, S. W.: Improvements to a MODIS global terrestrial evapotranspiration algorithm, Remote Sens. Environ., 115, 1781-1800, 2011.

Mueller, B. and Seneviratne, S.: Systematic land climate and evapotranspiration biases in CMIP5 simulations, Geophys. Res. Lett., 41, 128-134, 2014.

Mueller, B., Seneviratne, S. I., Jimenez, C., Corti, T., Hirschi, M., Balsamo, G., Ciais, P., Dirmeyer, P., Fisher, J. B., Guo, Z., Jung, M., Maignan, F., McCabe, M. F., Reichle, R., Reichstein, M., Rodell, M., Sheffield, J., Teuling, A. J., Wang, K., Wood, E. F., and Zhang, Y.: Evaluation of global observations-based evapotranspiration datasets and IPCC AR4 simulations, Geophys. Res. Lett., 38, L06402, doi:10.1029/2010GL046230, 2011.

Mueller, B., Hirschi, M., Jimenez, C., Ciais, P., Dirmeyer, P. A., Dolman, A. J., Fisher, J. B., Jung, M., Ludwig, F., Maignan, F., Miralles, D. G., McCabe, M. F., Reichstein, M., Sheffield, J., Wang, K., Wood, E. F., Zhang, Y., and Seneviratne, S. I.: Benchmark products for land evapotranspiration: LandFluxEVAL multi-data set synthesis, Hydrol. Earth Syst. Sci., 17, 3707-3720, doi:10.5194/hess-17-3707-2013, 2013.

Peng, J. and Loew, A.: Evaluation of Daytime Evaporative Fraction from MODIS TOA Radiances Using FLUXNET Observations, Remote Sens., 6, 5959-5975, 2014.

Peng, J., Borsche, M., Liu, Y., and Loew, A.: How representative are instantaneous evaporative fraction measurements of daytime fluxes?, Hydrol. Earth Syst. Sci., 17, 3913-3919, doi:10.5194/hess-17-3913-2013, 2013a.

Peng, J., Liu, Y., Zhao, X., and Loew, A.: Estimation of evapotranspiration from MODIS TOA radiances in the Poyang Lake basin, China, Hydrol. Earth Syst. Sci., 17, 1431-1444, doi:10.5194/hess-17-1431-2013, 2013b.

Priestley, C. and Taylor, R.: On the assessment of surface heat flux and evaporation using large-scale parameters, Mon. Weather Rev., 100, 81-92, 1972.

Qiu, J.: China: the third pole, Nature News, 454, 393-396, 2008.

Roerink, G. J., Su, Z., and Menenti, M.: S-SEBI: A simple remote sensing algorithm to estimate the surface energy balance, Phys. Chem. Earth Pt. B, 25, 147-157, 2000.

Sellers, P., Dickinson, R., Randall, D., Betts, A., Hall, F., Berry, J., Collatz, G., Denning, A., Mooney, H., and Nobre, C.: Modeling the exchanges of energy, water, and carbon between continents and the atmosphere, Science, 275, 502-509, 1997.

Shi, Q. and Liang, S.: Characterizing the surface radiation budget over the Tibetan Plateau with ground-measured, reanalysis, and remote sensing data sets: 2 . Spatiotemporal analysis, J. Geophys. Res.-Atmos., 118, 8921-8934, 2013a.

Shi, Q., and Liang, S.: Characterizing the surface radiation budget over the Tibetan Plateau with ground-measured, reanalysis, 
and remote sensing data sets: 1 . Methodology, J. Geophys. Res.Atmos., 118, 9642-9657, 2013b.

Shi, Q. and Liang, S.: Surface-sensible and latent heat fluxes over the Tibetan Plateau from ground measurements, reanalysis, and satellite data, Atmos. Chem. Phys., 14, 5659-5677, doi:10.5194/acp-14-5659-2014, 2014.

Stackhouse, P., Gupta, S., Cox, S., Zhang, T., Mikovitz, J., and Hinkelman, L.: 24.5-Year SRB Data Set Released, GEWEX News, 21, 10-12, 2011.

$\mathrm{Su}, \mathrm{Z}$. : The Surface Energy Balance System (SEBS) for estimation of turbulent heat fluxes, Hydrol. Earth Syst. Sci., 6, 85-100, doi:10.5194/hess-6-85-2002, 2002.

Vinukollu, R. K., Meynadier, R., Sheffield, J., and Wood, E. F.: Multi-model, multi-sensor estimates of global evapotranspiration: climatology, uncertainties and trends, Hydrol. Process., 25, 3993-4010, 2011a.

Vinukollu, R. K., Wood, E. F., Ferguson, C. R., and Fisher, J. B.: Global estimates of evapotranspiration for climate studies using multi-sensor remote sensing data: Evaluation of three processbased approaches, Remote Sens. Environ., 115, 801-823, $2011 \mathrm{~b}$.

Wang, K. and Dickinson, R. E.: A review of global terrestrial evapotranspiration: Observation, modeling, climatology, and climatic variability, Rev. Geophys., 50, RG2005, doi:10.1029/2011RG000373, 2012.

Xu, X., Lu, C., Shi, X., and Gao, S.: World water tower: An atmospheric perspective, Geophys. Res. Lett., 35, L20815, doi:10.1029/2008GL035867, 2008.

Yanai, M. and Li, C.: Mechanism of heating and the boundary layer over the Tibetan Plateau, Mon. Weather Rev., 122, 305-323, 1994.

Yang, K., Koike, T., and Yang, D.: Surface flux parameterization in the Tibetan Plateau, Bound.-Lay. Meteorol., 106, 245-262, 2003.
Yang, K., Chen, Y.-Y., and Qin, J.: Some practical notes on the land surface modeling in the Tibetan Plateau, Hydrol. Earth Syst. Sci., 13, 687-701, doi:10.5194/hess-13-687-2009, 2009.

Yang, K., Wu, H., Qin, J., Lin, C., Tang, W., and Chen, Y.: Recent climate changes over the Tibetan Plateau and their impacts on energy and water cycle: A review, Global Planet. Change, 112, 79-91, 2014.

You, Q., Fraedrich, K., Min, J., Kang, S., Zhu, X., Pepin, N., and Zhang, L.: Observed surface wind speed in the Tibetan Plateau since 1980 and its physical causes, Int. J. Climatol., 34, 18731882, 2014.

Zhang, K., Kimball, J. S., Nemani, R. R., and Running, S. W.: A continuous satellite-derived global record of land surface evapotranspiration from 1983 to 2006, Water Resour. Res., 46, W09522, doi:10.1029/2009WR008800, 2010.

Zhang, K., Kimball, J. S., Nemani, R. R., Running, S. W., Hong, Y., Gourley, J. J., and Yu, Z.: Vegetation Greening and Climate Change Promote Multidecadal Rises of Global Land Evapotranspiration, Scientific Reports, 5, 15956, doi:10.1038/srep15956, 2015.

Zhang, K., Kimball, J. S., and Running, S. W.: A review of remote sensing based actual evapotranspiration estimation, WIREs Water, doi:10.1002/wat2.1168, 2016.

Zhang, Y., Liu, C., Tang, Y., and Yang, Y.: Trends in pan evaporation and reference and actual evapotranspiration across the Tibetan Plateau, J. Geophys. Res.-Atmos., 112, D12110, doi:10.1029/2006JD008161, 2007.

Zhang, Y., Peña-Arancibia, J. L., McVicar, T. R., Chiew, F. H. S., Vaze, J., Liu, C., Lu, X., Zheng, H., Wang, Y., Liu, Y. Y., Miralles, D. G., and Pan, M.: Multi-decadal trends in global terrestrial evapotranspiration and its components, Scientific Reports, 6, 19124, doi:10.1038/srep19124, 2016. 